\title{
Phase stability of ScN-based solid solutions for thermoelectric applications from first-principles calculations
}

Sit Kerdsongpanya, Björn Alling and Per Eklund

\section{Linköping University Post Print}

\section{Tweet}

N.B.: When citing this work, cite the original article.

Original Publication:

Sit Kerdsongpanya, Björn Alling and Per Eklund, Phase stability of ScN-based solid solutions for thermoelectric applications from first-principles calculations, 2013, Journal of Applied Physics, (114), 7.

http://dx.doi.org/10.1063/1.4818415

Copyright: American Institute of Physics (AIP) http://www.aip.org/ 


\title{
Phase stability of ScN-based solid solutions for thermoelectric applications from first-principles calculations
}

\author{
Sit Kerdsongpanya, ${ }^{\text {a) }}$ Björn Alling, and Per Eklund \\ Thin Film Physics Division, Department of Physics, Chemistry, and Biology (IFM), Linköping University, \\ SE-581 83 Linköping, Sweden
}

(Received 17 July 2013; accepted 29 July 2013; published online 21 August 2013)

\begin{abstract}
We have used first-principles calculations to investigate the trends in mixing thermodynamics of ScN-based solid solutions in the cubic B1 structure. 13 different $\mathrm{Sc}_{1-\mathrm{x}} \mathrm{M}_{\mathrm{x}} \mathrm{N}(\mathrm{M}=\mathrm{Y}, \mathrm{La}, \mathrm{Ti}, \mathrm{Zr}, \mathrm{Hf}$, $\mathrm{V}, \mathrm{Nb}, \mathrm{Ta}, \mathrm{Gd}, \mathrm{Lu}, \mathrm{Al}, \mathrm{Ga}, \mathrm{In})$ and three different $\mathrm{ScN}_{1-\mathrm{x}} \mathrm{A}_{\mathrm{x}}(\mathrm{A}=\mathrm{P}, \mathrm{As}, \mathrm{Sb})$ solid solutions are investigated and their trends for forming disordered or ordered solid solutions or to phase separate are revealed. The results are used to discuss suitable candidate materials for different strategies to reduce the high thermal conductivity in $\mathrm{ScN}$-based systems, a material having otherwise promising thermoelectric properties for medium and high temperature applications. Our results indicate that at a temperature of $\mathrm{T}=800{ }^{\circ} \mathrm{C}, \mathrm{Sc}_{1-\mathrm{x}} \mathrm{Y}_{\mathrm{x}} \mathrm{N} ; \mathrm{Sc}_{1-\mathrm{x}} \mathrm{La}_{\mathrm{x}} \mathrm{N} ; \mathrm{Sc}_{1-\mathrm{x}} \mathrm{Gd}_{\mathrm{x}} \mathrm{N}, \mathrm{Sc}_{1-\mathrm{x}} \mathrm{Ga}_{\mathrm{x}} \mathrm{N}$, and $\mathrm{Sc}_{1-\mathrm{x}} \mathrm{In}_{\mathrm{x}} \mathrm{N}$; and $\mathrm{ScN}_{1-x} \mathrm{P}_{\mathrm{x}}, \mathrm{ScN}_{1-\mathrm{x}} \mathrm{As}_{\mathrm{x}}$, and $\mathrm{ScN}_{1-\mathrm{x}} \mathrm{Sb}_{\mathrm{x}}$ solid solutions have phase separation tendency, and thus, can be used for forming nano-inclusion or superlattices, as they are not intermixing at high temperature. On the other hand, $\mathrm{Sc}_{1-\mathrm{x}} \mathrm{Ti}_{\mathrm{x}} \mathrm{N}, \mathrm{Sc}_{1-\mathrm{x}} \mathrm{Zr}_{\mathrm{x}} \mathrm{N}, \mathrm{Sc}_{1-\mathrm{x}} \mathrm{Hf}_{\mathrm{x}} \mathrm{N}$, and $\mathrm{Sc}_{1-\mathrm{x}} \mathrm{Lu}_{\mathrm{x}} \mathrm{N}$ favor disordered solid solutions at $\mathrm{T}=800^{\circ} \mathrm{C}$. Thus, the $\mathrm{Sc}_{1-\mathrm{x}} \mathrm{Lu}_{\mathrm{x}} \mathrm{N}$ system is suggested for a solid solution strategy for phonon scattering as Lu has the same valence as Sc and much larger atomic mass. C 2013 AIP Publishing LLC. [http://dx.doi.org/10.1063/1.4818415]
\end{abstract}

\section{INTRODUCTION}

$\mathrm{ScN}$ is a promising material for medium and high temperature thermoelectric applications since it has suitable thermal and electrical properties for thermoelectric application, such as high melting point $(2900 \mathrm{~K}),{ }^{1,2}$ being an n-type semiconductor with indirect band gap of $0.9-1.6 \mathrm{eV}$ and a wide range of electron mobility $30-172 \mathrm{~cm}^{2} \mathrm{~V}^{-1} \mathrm{~s}^{-1}$ with carrier concentrations reported to vary from $10^{18}$ to $10^{22} \mathrm{~cm}^{-3} .^{3-7}$ In terms of thermoelectric properties, we discovered that $\mathrm{ScN}$ thin films have high thermoelectric power factor $\left(S^{2} \sigma\right)$ of $2.5 \times 10^{-3} \mathrm{~W} /\left(\mathrm{m} \cdot \mathrm{K}^{2}\right)$ at $800 \mathrm{~K}$ where the thermoelectric power factor is the product of Seebeck coefficient $(S)$ and electrical conductivity $(\sigma) .{ }^{8}$ Recently, this was confirmed by Burmistrova et al. who reported a thermoelectric power factor of $\mathrm{ScN}$ up to $3.3 \times 10^{-3} \mathrm{~W} /\left(\mathrm{m} \cdot \mathrm{K}^{2}\right)$ at $840 \mathrm{~K}$ due to low metallic-like electrical resistivity $(7.4 \mu \Omega \mathrm{m})$ with retained relatively large Seebeck coefficient of $-156 \mu \mathrm{V} / \mathrm{K} .{ }^{9}$ These power factors are comparable to state of the art thermoelectric material such as pure $\mathrm{Bi}_{2} \mathrm{Te}_{3}$ or PbTe. ${ }^{10-12}$ The value is high considering that it is obtained for a nitride material without any deliberate optimization of doping and has been suggested to be related to electronic structure effects of nitrogen vacancies and oxygen incorporation..$^{9,13}$

However, for most practical applications, the thermoelectric figure of merit $(Z T)$ of $\mathrm{ScN}$ is too low. ZT is defined as $S^{2} \sigma T / \kappa$, where $T$ is the absolute temperature, $\kappa$ is the sum of electrical and lattice thermal conductivity, $\kappa=\kappa_{e l}+\kappa_{p h}$. For pure $\mathrm{ScN}, Z T$ is about $0.2-0.3$ at $800 \mathrm{~K} .{ }^{8,9}$ This is due to the high total thermal conductivity of about $8.3 \mathrm{~W} / \mathrm{m} \cdot \mathrm{K}^{2}$ at $800 \mathrm{~K}^{9,14}$ Thus, to improve the ZT of $\mathrm{ScN}$, the lattice thermal

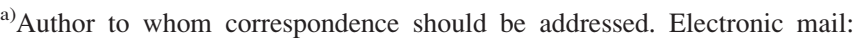
sitke@ifm.liu.se.
}

conductivity needs to be reduced. Standard strategies for other thermoelectric materials for lattice thermal conductivity reduction include alloying, construction of superlattices, nanoinclusions, or grain boundaries. ${ }^{10,15-22}$ In addition, Sc is naturally isotope-pure and $\mathrm{ScN}$ thus lacks, with the exception of the small effect of $0.4 \%{ }^{15} \mathrm{~N},{ }^{23}$ isotope reduction of thermal conductivity. Consequently, the possibilities to substantially reduce the thermal conductivity by alloying or nanostructure engineering are particularly promising in this material. If the thermal conductivity can be reduced, ScN-based materials could potentially be applied at elevated temperatures, possibly as high as around $800^{\circ} \mathrm{C}$ where diffusion can be activated. This means that the thermodynamics of mixing between $\mathrm{ScN}$ and the alloying or superlattice component becomes relevant. Superlattices might intermix, alloys could order or phaseseparate, and nanostructures might be dissolved in the matrix. All these processes could affect, negatively or positively, thermoelectric properties. The thermodynamics of mixing is also of relevance for the possibility of bulk synthesis. Thin film growth of multicomponent nitrides are typically done at nonequilibrium conditions where metastable alloys can be formed also in immiscible systems. ${ }^{24,25}$ However, if there is a thermodynamic driving force for decomposition, nanostructure design can be performed by annealing of metastable thin-film alloys. There are a number of investigations demonstrating the effects of diffusion in mixed nitride systems at high temperature, in particular, in thin films. For instance, it has been found that metastable nitride alloys might phase separate both by a spinodal-decomposition mechanism, for instance, in TiAlN, ${ }^{26,27}$ and by nucleation and growth as in ScAlN. ${ }^{28}$ The difference has been explained in terms of volume mismatch, favoring nucleation and growth, and the electronic structure as driving forces for phase separation, allowing for spinodal decomposition. ${ }^{29-31}$ These decomposition mechanisms give 
different nanostructure and could give different impact on thermoelectric properties. ${ }^{28,32,33}$ Thus, we need to carefully select suitable materials candidates for each different approach for thermal conductivity reduction in $\mathrm{ScN}$-based systems.

In this work, we perform a first-principles scan of the mixing thermodynamics and lattice spacing of $\mathrm{ScN}$ with 13 different nitrides and three other pnictides with possible relevance for design of thermoelectric properties. Thus, we are able to suggest candidate materials for the different design strategies to decrease the thermal conductivity of ScN-based systems at high temperatures.

\section{COMPUTATIONAL DETAILS}

In this study, we consider the mixing thermodynamics in order to determine phase stability of $\mathrm{Sc}_{1-\mathrm{x}} \mathrm{M}_{\mathrm{x}} \mathrm{N}$ and $\mathrm{ScN}_{1-\mathrm{x}} \mathrm{A}_{\mathrm{x}}$ alloy systems where $\mathrm{M}$ consists of early transition metals (Y, Ti, Zr, Hf, V, Nb, and Ta), rare earth metals (La, $\mathrm{Gd}$, and $\mathrm{Lu}$ ) and group-13 (Ga and In) and A consists of group-15 ( $\mathrm{P}, \mathrm{As}$, and $\mathrm{Sb})$. These nitride systems are chosen since they all can be found in the rock salt B1 structure, although in some cases other structures are the ground state under ambient conditions. We start by considering the mixing enthalpy which is calculated as

$$
\Delta H_{m i x}(x)=H_{\left(S c_{1-x} M_{x} N / S c N_{1-x} A_{x}\right)}-(1-x) H_{S c N}-x H_{M N / S c A},
$$

where the enthalpies are considered at zero pressure as the energies of each phase is taken at its corresponding equilibrium volume. The effect of increasing temperature can be assessed by calculation of the free energy

$$
\Delta G(x, T)=\Delta H_{m i x}(x)-T \Delta S(x),
$$

where $\Delta H(x)$ is the mixing enthalpy per formula unit and the mixing entropy $\Delta S(x)$ can be estimated from the mean-field approximation

$$
S_{m f}=-k_{B}\{x \ln (x)+(1-x) \ln (1-x)\},
$$

where $x$ is the fraction of considered solid solution material. This formula is a simplification of the real entropy and is used to obtain a guideline for effect of temperature on phase stability. Vibrational contributions are not included but are believed to be of no critical importance for the ability to draw qualitative conclusions about mixing trends at temperatures up to around $1000 \mathrm{~K}$, which was noted for the related system TiAlN (Ref. 34) and probably related to the high melting point of these nitrides. All calculations in this work were performed based on first-principles density functional calculations using the KohnSham equations ${ }^{35}$ and Projector Augmented Wave (PAW) method $^{36}$ as implemented in the Vienna Ab-initio Simulation Package (VASP) code. ${ }^{37,38}$ Two exchange-correlation energy approximations had been used in this study, (i) the generalized gradient approximation as given by Perdew-Burke-Ernzerhof (GGA-PBE) $^{39}$ for early transition metals, group-13 and-15 and (ii) the generalized gradient approximation with a Hubbard Coulomb term, ${ }^{40}$ the $U$ term, applied only to $4 f$ orbitals. The effective values $(U-J)$ are selected according to the determination in Ref. 41 as $6.5 \mathrm{eV}, 8 \mathrm{eV}$, and $9.5 \mathrm{eV}$ for $\mathrm{La}$, $\mathrm{Gd}$, and Lu, respectively. Note that in Ref. 41, they showed that for empty-, full-, and half-filled with strong spin-splitting of $4 f$ band, the $4 f$-states are positioned far below or above the Fermi level. Correspondingly, the exact value of the $U$ should have a small effect on mixing energetics.

In this study, to reveal the mixing trends, we have selected three types of configurations to each of the $\mathrm{ScN}$ based solid solutions. First, the clustering state is considered by the separate calculation of the pure binary nitrides. Second, substitutionally disordered solid solutions of $\mathrm{Sc}_{1-\mathrm{x}} \mathrm{M}_{\mathrm{x}} \mathrm{N}$ and $\mathrm{ScN}_{1-\mathrm{x}} \mathrm{A}_{\mathrm{x}}$ on the underlying rock salt (B1) lattice are generated using a special quasirandom structures $(\mathrm{SQSs})^{42}$-based approach for the composition $\mathrm{x}=0.25,0.50$, and 0.75 . To obtain converged total energies, 128 atoms supercells are used, which are based on a $4 \times 4 \times 4$ repetition of the fcc-unitcell and consisting of 64 atoms on each sublattice. The pair correlation functions, quantifying the configurational state of a structure, ${ }^{32,43}$ are for these SQS structures identical to the ideal disordered system on the first two nearest neighbor shell and differing with less than 0.04 on the first seven shells for all compositions. Finally, ordered configurations are represented by the $\mathrm{B} 1-\mathrm{L} 1_{0}(\mathrm{CuAu})$ and $\mathrm{B} 1-\mathrm{L}_{1}(\mathrm{CuPt})$ ordering with composition $\mathrm{x}=0.50$ for all systems in this study. These two structures are chosen since they represent the maximum ordering possible on the first and second metal coordination shells, respectively, on the fcc lattice. These two coordination shells are often dominating the effective cluster interactions and thus, the energies of $\mathrm{B} 1-\mathrm{L} 1_{0}$ and $\mathrm{B} 1-\mathrm{L} 1_{1}$ should contrast strongly to the phase separated state and together with clustering and the SQS structure give a good estimate of the energy span of different $\mathrm{Sc}_{0.5} \mathrm{M}_{0.5} \mathrm{~N}$ and $\mathrm{ScN}_{0.5} \mathrm{~A}_{0.5}$ alloys. The $\mathrm{B} 1-\mathrm{L1}_{1}$ structure has also been predicted as the ground state in the isostructural $\mathrm{Zr}_{0.5} \mathrm{Gd}_{0.5} \mathrm{~N}$ (Ref. 44) and has been observed experimentally for $\mathrm{Ti}_{0.5} \mathrm{~W}_{0.5} \mathrm{~N} .{ }^{33}$ In addition, we included in this study also the $\mathrm{ScTaN}_{2}$-type hexagonal structure (space group $\mathrm{Pb}_{3} / \mathrm{mmc}$ ) consisting of alternating layer of Sc-N-Ta-N-Sc. This structure can be considered an inherent nanolaminate (more details, see, Refs. 45 and 46) which possibly could give interesting thermoelectric properties as in similar systems such as misfit layered cobaltates or $\mathrm{TiS}_{2}{ }^{47-49}$ A plane wave cut-off of $400 \mathrm{eV}$ was used with the k-point mesh of $7 \times 7 \times 7$ points for 128 cells and $21 \times 21 \times 21$ points for the binary system. In all systems, the internal coordinates of atoms were fully relaxed and in the case of ordered alloys also the cell shape was relaxed.

\section{RESULTS AND DISCUSSION}

Below we report the results of our systematic investigation of mixing thermodynamics in the $\mathrm{Sc}_{1-\mathrm{x}} \mathrm{M}_{\mathrm{x}} \mathrm{N}$ and $\mathrm{ScN}_{1-\mathrm{x}} \mathrm{A}_{\mathrm{x}}$ systems. The section is organized such that the different candidate systems are divided in subsections depending on the location of $\mathrm{M}$ (or A) place in the periodic table.

\section{A. $S c_{1-x} Y_{x} N$}

The calculated mixing enthalpy of the $\mathrm{Sc}_{1-\mathrm{x}} \mathrm{Y}_{\mathrm{x}} \mathrm{N}$ solid solution is shown in Figure 1(a). $\mathrm{Sc}_{1-\mathrm{X}} \mathrm{Y}_{\mathrm{X}} \mathrm{N}$ exhibits a 
(a)

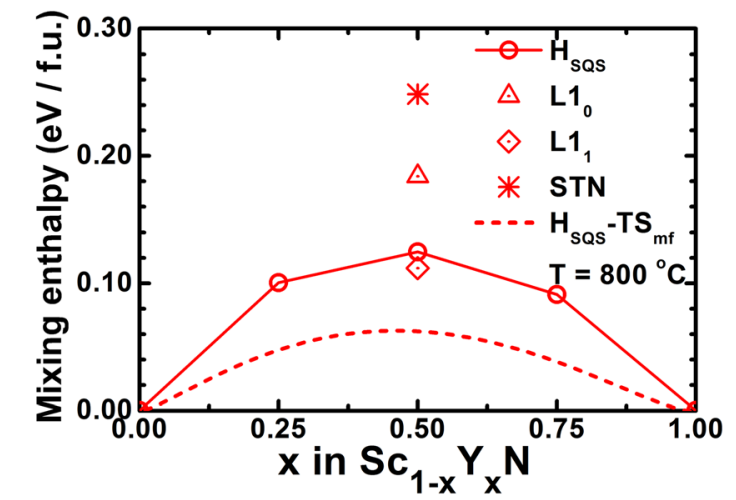

(b)

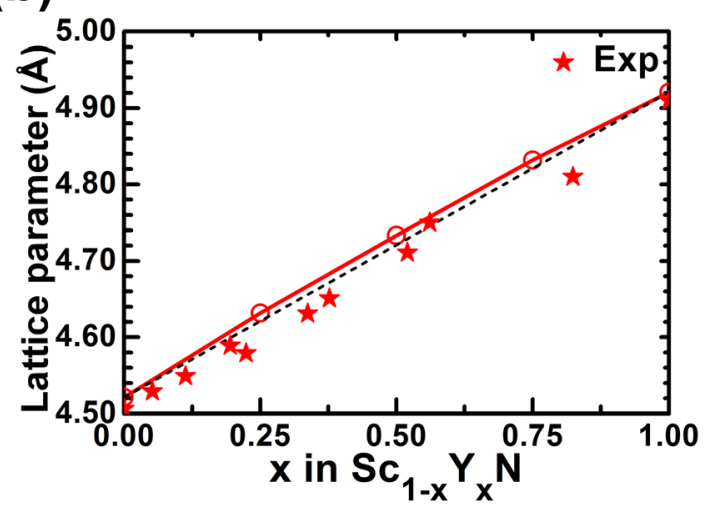

FIG. 1. (a) Comparison of the calculated mixing enthalpies of substitutionally disordered solid solution, $\mathrm{B} 1-\mathrm{L} 1_{0}$ and $\mathrm{B} 1-1_{1}$ ordered solid solution and $\mathrm{ScTaN}_{2}$-type structure phase, respectively, of $\mathrm{Sc}_{1-\mathrm{x}} \mathrm{Y}_{\mathrm{x}} \mathrm{N}$, as a function of YN content. (b) Calculated equilibrium lattice parameter for rocksalt (B1) $\mathrm{Sc}_{1-\mathrm{x}} \mathrm{Y}_{\mathrm{x}} \mathrm{N}$ solid solution as a function of $\mathrm{YN}$ content. The black line indicates Vegard's rule. Experimental data from the work of Gregoire et al. are shown with stars. ${ }^{50}$

positive symmetric mixing enthalpy curve for the random solid solution over entire composition with the highest value of about $0.12 \mathrm{eV} / \mathrm{f}$.u. at $\mathrm{x}=0.50$. For the considered ordered alloys, the B1-L1 1 compound is similar to the SQS in enthalpy while the $\mathrm{B} 1-\mathrm{L1}_{0}$ and the $\mathrm{ScLaN}_{2}$ structure are considerably higher. Thus, $\mathrm{Sc}_{1-\mathrm{x}} \mathrm{Y}_{\mathrm{x}} \mathrm{N}$ shows an energetic driving force for phase separation into $\mathrm{ScN}$ and $\mathrm{YN}$. The reason can be seen from Table I; the calculated binary lattice parameters are $a_{S c N}=4.52 \AA$ and $a_{Y N}=4.92 \AA$. This means that $\mathrm{YN}$ has a lattice parameter $9 \%$ larger than $\mathrm{ScN}$ translating to a volume mismatch of $29 \%$. This mismatch prevents the $\mathrm{Sc}_{1-\mathrm{x}} \mathrm{Y}_{\mathrm{x}} \mathrm{N}$ system from being thermodynamically stable as a solid solution. Moreover, Figure 1(b) shows the calculated lattice parameter of $\mathrm{Sc}_{1-\mathrm{x}} \mathrm{Y}_{\mathrm{x}} \mathrm{N}$ solid solution. The plot shows a positive deviation from the linear Vegard's rule. This behavior has been observed previously for highly sizemismatched nitride solid solutions such as $\mathrm{Sc}_{1-\mathrm{x}} \mathrm{Al}_{\mathrm{x}} \mathrm{N}^{28}$ and $\mathrm{Ti}_{1-\mathrm{x}} \mathrm{Gd}_{\mathrm{x}} \mathrm{N}^{44}$ and has been explained with the asymmetry of the binding energy curves making it more difficult to drastically compress the larger nitride as compared to expand the smaller. When we include the effect of temperature at $\mathrm{T}=800^{\circ} \mathrm{C}$ and study the free energy of mixing, the result still shows positive symmetric mixing free energy curve with small drop in magnitude. This result confirms that even at high temperature, $\mathrm{ScN}$ and $\mathrm{YN}$ will tend to phase separate if
TABLE I. Calculated equilibrium and experimental lattice parameters for rocksalt (B1) of $\mathrm{Sc}_{1-\mathrm{x}} \mathrm{M}_{\mathrm{x}} \mathrm{N}$ solid solution as a function of $\mathrm{MN}$ content, where $\mathrm{M}=\mathrm{Y}, \mathrm{Ti}, \mathrm{Hf}, \mathrm{Zr}, \mathrm{V}, \mathrm{Nb}, \mathrm{Ta}, \mathrm{Ga}, \mathrm{In} \mathrm{La}, \mathrm{Gd}$, and $\mathrm{Lu}$ for Sc sublattice mixtures and $\mathrm{B} 1$ solid solutions of $\mathrm{ScN}_{1-\mathrm{x}} \mathrm{A}_{\mathrm{x}}$ as a function of ScA content where $\mathrm{A}=\mathrm{P}, \mathrm{As}$, and $\mathrm{Sb}$ for $\mathrm{N}$ sublattice mixtures.

\begin{tabular}{lccccc}
\hline \hline & \multicolumn{5}{c}{ Calculated lattice parameter/experimental lattice parameter $(\AA)$} \\
\cline { 2 - 6 } Materials & $\mathrm{x}=0$ & $\mathrm{x}=0.25$ & $\mathrm{x}=0.50$ & $\mathrm{x}=0.75$ & $\mathrm{x}=1.0$ \\
\hline $\mathrm{Sc}_{1-\mathrm{x}} \mathrm{Y}_{\mathrm{x}} \mathrm{N}$ & $4.52 / 4.500^{\mathrm{a}}$ & 4.63 & 4.73 & 4.83 & $4.92 / 4.89,^{\mathrm{a}} 4.91^{\mathrm{c}}$ \\
$\mathrm{Sc}_{1-\mathrm{x}} \mathrm{Ti}_{\mathrm{x}} \mathrm{N}$ & $4.512^{\mathrm{b}}$ & 4.44 & 4.37 & 4.31 & $4.25 / 4.25^{\mathrm{b}}$ \\
$\mathrm{Sc}_{1-\mathrm{x}} \mathrm{Zr}_{\mathrm{x}} \mathrm{N}$ & 4.54 & 4.56 & 4.58 & $4.60 / 4.58^{\mathrm{c}}$ \\
$\mathrm{Sc}_{1-\mathrm{x}} \mathrm{Hf}_{\mathrm{x}} \mathrm{N}$ & 4.52 & 4.52 & 4.53 & $4.53 / 4.52^{\mathrm{c}}$ \\
$\mathrm{Sc}_{1-\mathrm{x}} \mathrm{V}_{\mathrm{x}} \mathrm{N}$ & 4.41 & 4.31 & 4.22 & $4.12 / 4.12^{\mathrm{c}}$ \\
$\mathrm{Sc}_{1-\mathrm{x}} \mathrm{Nb}_{\mathrm{x}} \mathrm{N}$ & 4.48 & 4.47 & 4.46 & $4.45 / 4.39^{\mathrm{c}}$ \\
$\mathrm{Sc}_{1-\mathrm{x}} \mathrm{Ta}_{\mathrm{x}} \mathrm{N}$ & 4.47 & 4.45 & 4.43 & $4.42 / 4.36^{\mathrm{c}}$ \\
$\mathrm{Sc}_{1-\mathrm{x}} \mathrm{Ga}_{\mathrm{x}} \mathrm{N}$ & 4.47 & 4.43 & 4.39 & 4.27 \\
$\mathrm{Sc}_{1-\mathrm{x}} \mathrm{In}_{\mathrm{x}} \mathrm{N}$ & 4.57 & 4.62 & 4.66 & 4.71 \\
$\mathrm{Sc}_{1-\mathrm{x}} \mathrm{La}_{\mathrm{x}} \mathrm{N}$ & 4.77 & 5.01 & 5.21 & $5.34 / 5.29^{\mathrm{c}}$ \\
$\mathrm{Sc}_{1-\mathrm{x}} \mathrm{Gd}_{\mathrm{x}} \mathrm{N}$ & 4.64 & 4.76 & 4.88 & $4.98 / 4.98^{\mathrm{d}}$ \\
$\mathrm{Sc}_{1-\mathrm{x}} \mathrm{Lu}_{\mathrm{x}} \mathrm{N}$ & 4.53 & 4.56 & 4.58 & 4.61 \\
$\mathrm{ScN}_{1-\mathrm{x}} \mathrm{P}_{\mathrm{x}}$ & 4.74 & 4.94 & 5.15 & $5.31 / 5.30^{\mathrm{e}}$ \\
$\mathrm{ScN}_{1-\mathrm{x}} \mathrm{As}_{\mathrm{x}}$ & 4.81 & 5.08 & 5.32 & $5.49 / 5.46^{\mathrm{e}}$ \\
$\mathrm{ScN}_{1-\mathrm{x}} \mathrm{Sb}_{\mathrm{x}}$ & 5.01 & 5.41 & 5.68 & 5.89 \\
\hline \hline
\end{tabular}

${ }^{\mathrm{a}}$ Reference 50 .

${ }^{\mathrm{b}}$ Reference 52

${ }^{\mathrm{c}}$ Reference 66.

${ }^{\mathrm{d}}$ Reference 67.

${ }^{\mathrm{e}}$ Reference 68

diffusion is activated in the system. Experimentally, thin films of $\mathrm{Sc}_{1-\mathrm{x}} \mathrm{Y}_{\mathrm{x}} \mathrm{N}$ solid solutions have been deposited by Gregoire et al. ${ }^{50}$ As can be seen in Fig. 1(b) the measured lattice spacing has good agreement with our calculations which is a strong indication that the films are solid solutions and not phase separated. PVD synthesis is a non-equilibrium technique well known to be able to grow films of metastable solid solutions in thermodynamically immiscible nitride alloy systems due to limited diffusion during growth. ${ }^{26}$ Our calculations predict that a high temperature annealing experiment carried out on such films would result in an initiation of phase separation when diffusion is activated. Since the driving force for separation in $\mathrm{Sc}_{1-\mathrm{x}} \mathrm{Y}_{\mathrm{x}} \mathrm{N}$ is the volume mismatch, phase separation would need the nucleation of large enough domains that could relax to the respective lattice spacing corresponding to the composition of the domains. On the other hand, fully coherent spinodal decomposition is not predicted to take place.

\section{B. $\mathrm{Sc}_{1-x} \mathrm{Ti}_{x} \mathrm{~N}, \mathrm{Sc}_{1-\mathrm{x}} \mathrm{Zr} \mathrm{r}_{x} \mathrm{~N}$, and $\mathrm{Sc}_{1-x} \mathrm{Hf}_{x} \mathrm{~N}$}

Figure 2(a) shows the calculated mixing enthalpies of $\mathrm{Sc}_{1-\mathrm{x}} \mathrm{Ti}_{\mathrm{x}} \mathrm{N}, \mathrm{Sc}_{1-\mathrm{x}} \mathrm{Zr}_{\mathrm{x}} \mathrm{N}$, and $\mathrm{Sc}_{1-\mathrm{x}} \mathrm{Hf}_{\mathrm{x}} \mathrm{N}$ solid solution system. All of the systems in this alloy family show lower mixing enthalpy than $\mathrm{Sc}_{1-\mathrm{X}} \mathrm{Y}_{\mathrm{X}} \mathrm{N}$ system and even negative for $\mathrm{Sc}_{1-\mathrm{x}} \mathrm{Zr}_{\mathrm{x}} \mathrm{N}$ and $\mathrm{Sc}_{1-\mathrm{x}} \mathrm{Hf}_{\mathrm{x}} \mathrm{N}$ disordered solid solutions over the entire composition range. The curves also show a considerable asymmetry with respect to equi-atomic concentrations, especially in $\mathrm{Sc}_{1-\mathrm{x}} \mathrm{Ti}_{\mathrm{x}} \mathrm{N}$ case where there is a strong deviation. These results show that $\mathrm{ScN}$ has higher tendency 
(a)

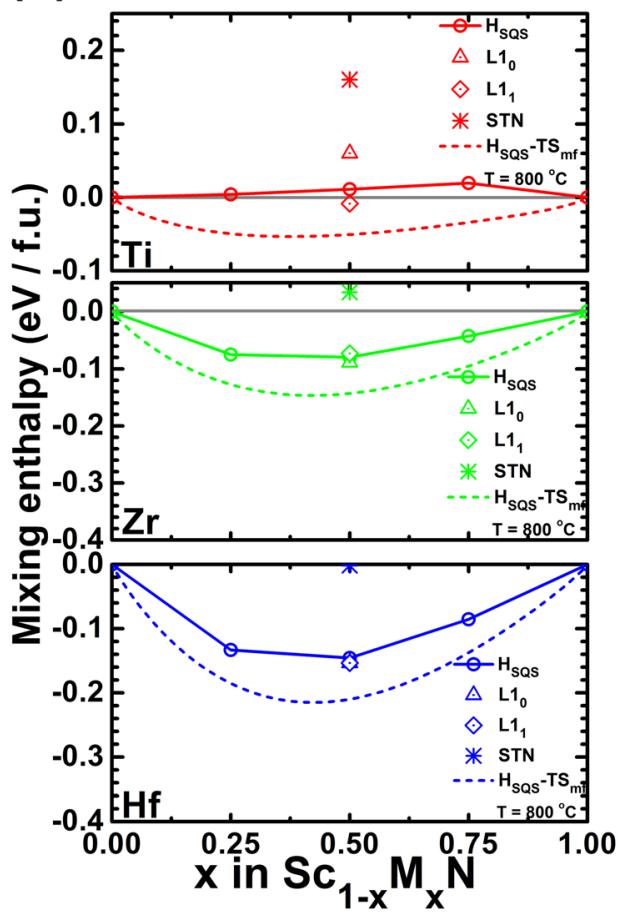

(b)

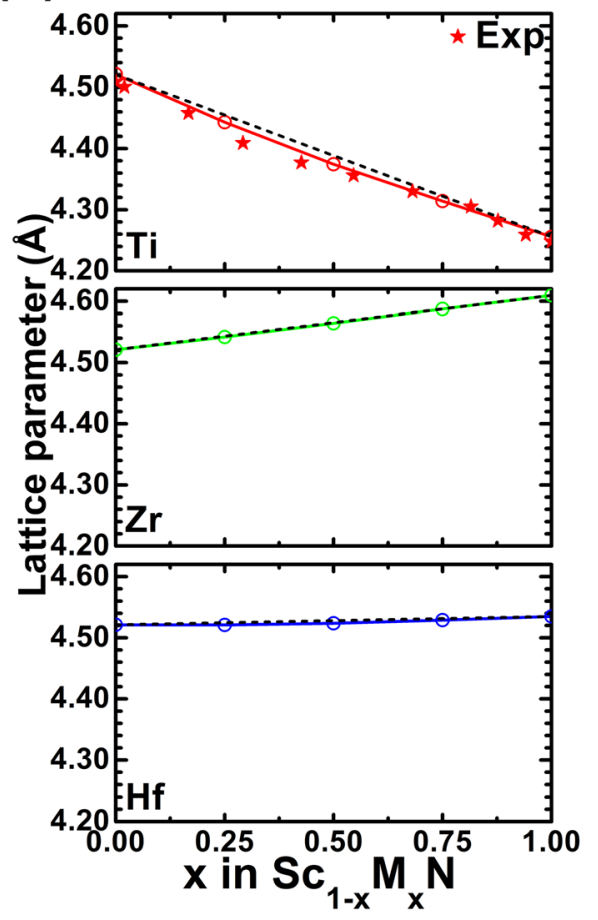

FIG. 2. (a) Comparison of the calculated mixing enthalpies of substitutionally disordered solid solution, B1-L10 and $\mathrm{B} 1-\mathrm{L} 1_{1}$ ordered solid solutions and $\mathrm{ScTaN}_{2}$-type structure phase of $\mathrm{Sc}_{1-\mathrm{x}} \mathrm{M}_{\mathrm{x}} \mathrm{N}$, as a function of MN content where $\mathrm{M}=\mathrm{Ti}, \mathrm{Zr}$, and $\mathrm{Hf}$, respectively. (b) Calculated equilibrium lattice parameter for rocksalt (B1) $\mathrm{Sc}_{1-\mathrm{x}} \mathrm{M}_{\mathrm{x}} \mathrm{N}$ solid solution as a function of $\mathrm{MN}$ content where $\mathrm{M}=\mathrm{Ti}, \mathrm{Zr}$, and Hf, respectively. The black line indicates Vegard's rule. For $\mathrm{Sc}_{1-x} \mathrm{Ti}_{x} \mathrm{~N}$, the experimental data from Gall et al. are shown with stars. ${ }^{52}$ to form solid solution with $\mathrm{TiN}, \mathrm{ZrN}$, and $\mathrm{HfN}$ than with YN. When we consider the effect of lattice parameter mismatch of this system, there is a small degree of lattice mismatch between $\mathrm{ScN}$ and $\mathrm{ZrN}$ or $\mathrm{HfN}$ but still high lattice mismatch between ScN and TiN (see Table I and Fig. 2(b)). In addition, TiN, $\mathrm{ZrN}$, and $\mathrm{HfN}$ have one extra $d$ electron as compared to $\mathrm{ScN}$ and YN. This extra $d$ electron can affects mixing energetics as has been found previously for the alloy of TiN with AlN. ${ }^{32}$ However, in opposite to the alloys of TiN, ZrN, and HfN with AlN, for $\mathrm{Sc}_{1-x} \mathrm{Ti}_{\mathrm{x}} \mathrm{N}, \mathrm{Sc}_{1-\mathrm{x}} \mathrm{Zr}_{\mathrm{x}} \mathrm{N}$, and $\mathrm{Sc}_{1-\mathrm{x}} \mathrm{Hf}_{\mathrm{x}} \mathrm{N}$ system, the extra d-electron can delocalize also over the Sc-sites which has empty $3 \mathrm{~d}-\mathrm{t} 2 \mathrm{~g}$ states. This results in a negative contribution to the enthalpy of mixing in these systems, and as can be observed in Fig. 2(a), to an asymmetric shape of the mixing enthalpy curve with respect to composition. The composition asymmetry shows that it is more favorable to dissolve a small amount of $\mathrm{Ti}, \mathrm{Zr}$, and $\mathrm{Hf}$ into $\mathrm{ScN}$ than a small amount of $\mathrm{Sc}$ in $\mathrm{TiN}, \mathrm{ZrN}$, and $\mathrm{HfN}$. This is qualitatively in line with the calculations of the dilute case in Ref. 51. It can be understood since the extra $d$ electrons with $t 2 g$ symmetry from $\mathrm{Ti}, \mathrm{Zr}$, and $\mathrm{Hf}$ has to occupy gradually higher energies of the empty Sc $3 d t 2 g$ state when their concentrations in the alloys increase. Since the lattice mismatch of $\mathrm{ZrN}$ and $\mathrm{HfN}$ with $\mathrm{ScN}$ is small, the effect of electronic structure dominates and yields a negative mixing enthalpy unlike TiN that has a large lattice mismatch that compensate for the electronic structure effect. In the case of $\mathrm{Sc}_{1-\mathrm{x}} \mathrm{Ti}_{\mathrm{X}} \mathrm{N}$, the ordered $\mathrm{B} 1-\mathrm{L} 1_{0}$ phase is higher in energy than the disordered solid solution and has a mixing enthalpy with respect to $\mathrm{TiN}$ and $\mathrm{ScN}$ of $0.060 \mathrm{eV} / \mathrm{f}$.u. The $\mathrm{B} 1-\mathrm{L} 1_{1}$ order on the other hand is lower and has a negative mixing enthalpy of $-0.08 \mathrm{eV} / \mathrm{f}$.u. The favoring of the B1$\mathrm{L} 1_{1}$ order has previously been observed for B1 systems, in particular, with size mismatch between the cations
$\mathrm{Zr}_{0.50} \mathrm{Gd}_{0.50} \mathrm{~N},{ }^{44} \mathrm{Ti}_{0.50} \mathrm{~W}_{0.50} \mathrm{~N},{ }^{33}$ and explained by the ability for relaxation of the metal-nitrogen bond lengths in this particular ordered structure where all second-nearest neighbor pairs on the metal fcc-sublattice are of different kinds. ${ }^{32}$ For $\mathrm{Sc}_{1-\mathrm{x}} \mathrm{Zr}_{\mathrm{x}} \mathrm{N}$, the $\mathrm{B} 1-\mathrm{L}_{0}$ order is just below the disordered solid solution with a mixing enthalpy of $-0.088 \mathrm{eV} / \mathrm{f}$.u. In this system with a small size difference, the $\mathrm{B} 1-\mathrm{L} 1_{1}$ phase is just above the SQS result. For $\mathrm{Sc}_{1-\mathrm{x}} \mathrm{Hf}_{\mathrm{x}} \mathrm{N}$, both ordered structures are almost degenerate with the SQS with the B1$\mathrm{L} 1_{1}$ being lowest with $\mathrm{H}_{\text {mix }}$ of $-0.153 \mathrm{eV} / \mathrm{f}$.u. In all these three systems, concentration appears to be the determining factor for the mixing thermodynamics rather than different configurations. Indeed, the estimation of mixing free energy including the mean field entropy at $800{ }^{\circ} \mathrm{C}$ clearly favors disordered solid solutions in $\mathrm{Sc}_{1-\mathrm{x}} \mathrm{Ti}_{\mathrm{x}} \mathrm{N}, \mathrm{Sc}_{1-\mathrm{x}} \mathrm{Zr}_{\mathrm{x}} \mathrm{N}$, and $\mathrm{Sc}_{1-\mathrm{x}} \mathrm{Hf}_{\mathrm{x}} \mathrm{N}$ systems. Our calculated lattice parameters of $\mathrm{Sc}_{1-\mathrm{x}} \mathrm{Ti}_{\mathrm{x}} \mathrm{N}$ solid solution are in agreement with existing experiments as can be seen in Fig. 2(b). The experiments by Gall et al. show that it is indeed possible to synthesize $\mathrm{Sc}_{1-\mathrm{x}} \mathrm{Ti}_{\mathrm{X}} \mathrm{N}$ solid solution thin films by reactive magnetron sputtering. ${ }^{52}$ The authors identified the solid solutions to be single phase B1 structure and did not report any signs of ordering. However, as for the $\mathrm{Sc}_{1-\mathrm{x}} \mathrm{Y}_{\mathrm{x}} \mathrm{N}$ case above, we are not aware of attempts to anneal such $\mathrm{Sc}_{1-\mathrm{x}} \mathrm{Ti}_{\mathrm{x}} \mathrm{N}$ solid solutions to allow for ordering or phase separation by high temperature induced diffusion.

\section{C. $S c_{1-x} V_{x} N, S c_{1-x} N b_{x} N$, and $S c_{1-x} T a_{x} N$}

The calculated mixing enthalpies of $\mathrm{Sc}_{1-x} \mathrm{~V}_{\mathrm{x}} \mathrm{N}$, $\mathrm{Sc}_{1-\mathrm{x}} \mathrm{Nb}_{\mathrm{x}} \mathrm{N}$, and $\mathrm{Sc}_{1-\mathrm{x}} \mathrm{Ta}_{\mathrm{x}} \mathrm{N}$ solid solution are shown in Figure 3(a). The results show that they have similar tendency as the systems described in Sec. III B; that is, low and negative mixing enthalpy and asymmetric curve meaning that 
(a)

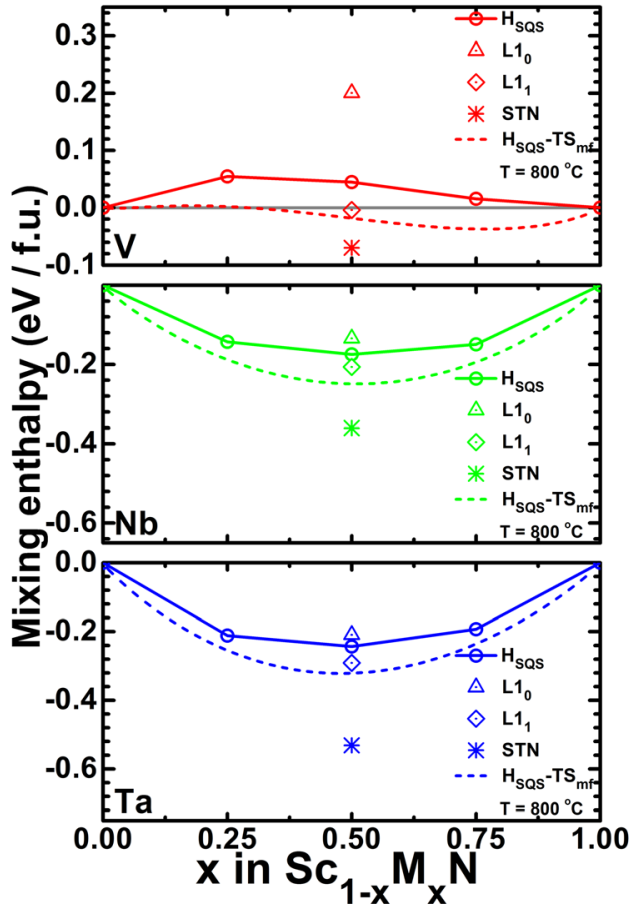

(b)

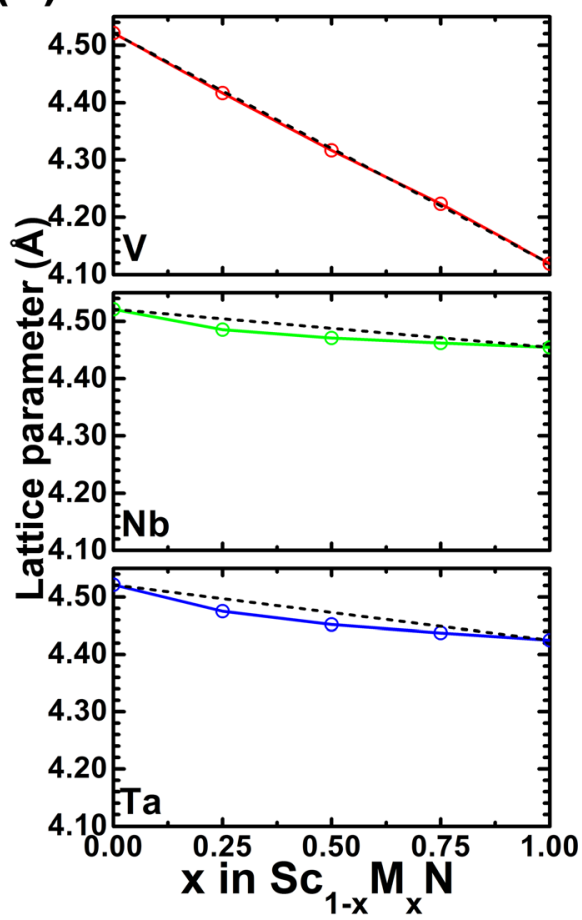

FIG. 3. (a) Comparison of the calculated mixing enthalpies of substitutionally disordered solid solution, B1-L1 and $\mathrm{B} 1-\mathrm{L}_{1}$ ordered solid solution and $\mathrm{ScTaN}_{2}$-type structure of $\mathrm{Sc}_{1-\mathrm{x}} \mathrm{M}_{\mathrm{x}} \mathrm{N}$, as a function of $\mathrm{MN}$ content where $\mathrm{M}=\mathrm{V}, \mathrm{Nb}$, and $\mathrm{Ta}$, respectively. (b) Calculated equilibrium lattice parameter for rocksalt (B1) $\mathrm{Sc}_{1-\mathrm{x}} \mathrm{M}_{\mathrm{x}} \mathrm{N}$ solid solution as a function of $\mathrm{MN}$ content where $\mathrm{M}=\mathrm{V}, \mathrm{Nb}$, and $\mathrm{Ta}$, respectively. The black line indicates Vegard's rule. these systems favor formation of solid solutions due to the effect of small lattice mismatch (see Table I) and effect of electronic structures, where $\mathrm{V}, \mathrm{Nb}$, and $\mathrm{Ta}$ have 2 extra $d$ electrons that can delocalize in the alloy with ScN. Figure 3(b) shows the deviation of lattice parameter with composition. It is a negative deviation from linear Vegard's rule, as in the previous system. At $x=0.50$, all three systems show a very low mixing enthalpy for $\mathrm{ScTaN}_{2}$-type structure, making this the ground state structure of the $\mathrm{Sc}_{1-\mathrm{x}} \mathrm{V}_{\mathrm{x}} \mathrm{N}, \mathrm{Sc}_{1-\mathrm{x}} \mathrm{Nb}_{\mathrm{x}} \mathrm{N}$, and $\mathrm{Sc}_{1-\mathrm{x}} \mathrm{Ta}_{\mathrm{x}} \mathrm{N}$ systems at $\mathrm{x}=0.50$. These results of our calculation agree with the fact that this phase has been experimentally synthesized in bulk as $\mathrm{ScTaN}_{2}$ and $\mathrm{ScNbN}_{2-\delta} .45,46$ Our results indicate that the corresponding phase, $\mathrm{ScVN}_{2}$, should exist in the Sc-V-N system. However, the latter system might deserve a more detailed future study as calculations have obtained energies for WC-type VN to be lower than the experimentally observed B1 VN phase making predictions in the VN-related system more difficult. ${ }^{53}$

The stability of the $\mathrm{ScTaN}_{2}$ phase can be explained by considering its structure. It consists of a layered structure with two subsystems which are rocksalt $\mathrm{ScN}$-like and a hexagonal related structure of TaN (WC structure type). ${ }^{45}$ When we consider the ground state structure of the binary phase of $\mathrm{TaN}$ and $\mathrm{NbN}$, there are competitive phases with hexagonal base structure (TaN has $\varepsilon$-phase structure and $\mathrm{NbN}$ has WC structure). ${ }^{54-56}$ These two binary systems have lower formation enthalpy than their rocksalt phase as plotted in Figure 4. Since $\mathrm{ScN}$ has the rocksalt structure and $\mathrm{NbN}$ and $\mathrm{TaN}$ have a hexagonal base structure as their lowest energy state, the combination of these two building blocks into a layered structure give, together with a possibility to delocalize $\mathrm{Nb}$ and Ta $d$-electrons also over the ScN-layers, an energetic driving force for this system to stabilize $\mathrm{ScTaN}_{2}$ structure. (a)

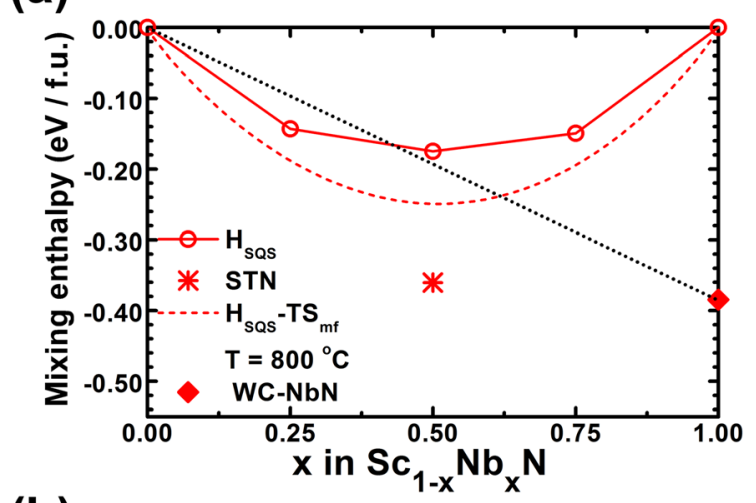

(b)

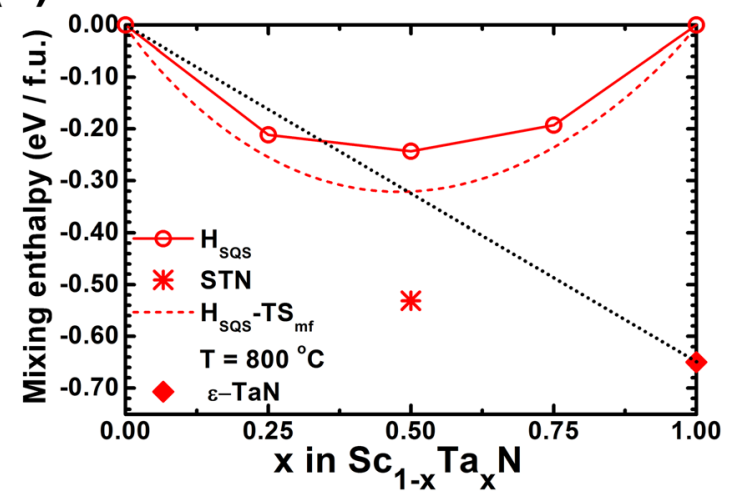

FIG. 4. Comparison of the calculated mixing enthalpies of substitutionally disordered solid solution, $\mathrm{ScTaN}_{2}$-type structure phase including their competitive hexagonal phase for (a) $\mathrm{Sc}_{1-\mathrm{x}} \mathrm{Nb}_{\mathrm{x}} \mathrm{N}$ and (b) $\mathrm{Sc}_{1-\mathrm{x}} \mathrm{Ta}_{\mathrm{x}} \mathrm{N}$. The dotted line indicates new equilibrium line. The value for $\mathrm{WC}, \mathrm{NbN}$, and $\varepsilon-\mathrm{TaN}$ are obtained from Refs. 54 and 56, respectively. 
This can be seen by the $\mathrm{ScTaN}_{2}$ structure being below also the line connecting the $\mathrm{B} 1-\mathrm{ScN}$ with hexagonal types of $\mathrm{TaN}$ and $\mathrm{NbN}$. Moreover, the $\mathrm{ScTaN}_{2}$ phase in these two material systems are stable also at $\mathrm{T}=800^{\circ} \mathrm{C}$ at least in comparison with the free energy of the disordered B1 solid solutions.

\section{D. $S c_{1-x} A l_{x} N, S c_{1-x} G a_{x} N$, and $S c_{1-x} I n_{x} N$}

The group-13 nitrides AlN, GaN, and $\mathrm{InN}$ crystallize in the hexagonal wurtzite structure as their ground state but can be transformed into the rock salt phase under high pressure. The B1 rock salt phase of AlN created at high pressure can be metastable also at ambient conditions ${ }^{57}$ while $\mathrm{B} 1 \mathrm{GaN}$ has been stabilized as thin interlayers. ${ }^{58}$ AlN is also known to be soluble as a metastable rock salt alloy in several rock salt transition metal nitrides, in particular, $\mathrm{Ti}_{1-\mathrm{x}} \mathrm{Al}_{\mathrm{x}} \mathrm{N} .{ }^{26}$ Thus, for our purpose, it is of interest to investigate their mixing tendency with $\mathrm{ScN}$.

Figure 5(a) shows the calculated mixing enthalpy of $\mathrm{ScN}$ with rock-salt $\mathrm{GaN}$ and $\mathrm{InN}$ while in the ScAlN system the $\mathrm{H}_{\text {mix }}$ data are taken from our previous work ${ }^{29}$ and included for comparison. Figure 5(a) shows that both the $\mathrm{GaN}$ and $\mathrm{InN}$ containing systems have lower, but still positive, mixing enthalpy than the $\mathrm{Sc}_{1-\mathrm{x}} \mathrm{Al}_{\mathrm{x}} \mathrm{N}$ meaning that $\mathrm{GaN}$ and InN have energetic driving force for isostructural phase separation with ScN but weaker than ScAlN. B1 GaN and InN have smaller lattice mismatch with $\mathrm{ScN}$ than rocksalt AlN does (Table I), which is the probable explanation for the lower mixing enthalpies. We note that our calculated value of the lattice parameter of $\mathrm{B} 1 \mathrm{GaN}, 4.27 \AA$, is considerably higher than the value $4.1 \AA$ reported for GaN stabilized as a multilayer with TiN. ${ }^{58}$ As all our other lattice spacing are showing excellent agreement with experiments, and that an extrapolation of the high-pressure lattice constant of B1 GaN to zero pressure seems to result in a value close to our, ${ }^{59}$ a reinvestigation of thin film multilayer stabilized $\mathrm{GaN}$ would be of interest.

When the temperature is considered at $800^{\circ} \mathrm{C}$ a fraction of the composition range becomes stable with respect to isostructural decomposition. The calculated lattice parameters of the $\mathrm{Sc}_{1-x} \mathrm{Ga}_{\mathrm{x}} \mathrm{N}$ solid solution show a positive deviation from the linear Vegard's rule (Figure 5(b)). For $\mathrm{Sc}_{1-\mathrm{x}} \mathrm{In}_{\mathrm{x}} \mathrm{N}$ the lattice parameters follow Vegard's rule almost exactly. $\mathrm{Al}, \mathrm{Ga}$, and In do not have $d$-electrons, they do not even have non-occupied d-states close to the Fermi level like ScN and YN. Therefore, there is no such electronic delocalization effect as has been discussed for the two previous families of systems contribution to mixing energy. On the other hand, the electronic structure effect opposing mixing as in the TiAlN system is not present either as the non-bonding $2 \mathrm{~g}$ states of $\mathrm{ScN}$ is unoccupied. ${ }^{29}$ This indicates that the only driving force for isostructural phase separation in this alloy family is the lattice mismatch of $\mathrm{ScN}$ and the group 13nitride. During the first stages of spinodal decomposition, the coherence of the lattice is kept intact and the different decomposition products cannot relax their volume. Thus, spinodal decomposition is unlikely in these systems. There is one concern for this material system on their structure after phase separation. Since our study considers ScN-based solid solutions, the mixing enthalpies of Figure 5(a) are calculated with respect to the rocksalt phase. However, as mentioned above, the binary phase structure at ambient pressure of AlN, GaN, and InN are wurtzite structure. We believe that these alloy systems should tend to phase separate through nucleation and growth of rocksalt $\mathrm{ScN}$ and wurtzite AIN, $\mathrm{GaN}$, or InN. This has been shown in the previous theoretical and experimental study on $\mathrm{Sc}_{1-\mathrm{x}} \mathrm{Al}_{\mathrm{x}} \mathrm{N}$ system by Höglund et $a l^{28}$ They synthesized metastable rocksalt $\mathrm{Sc}_{1-\mathrm{x}} \mathrm{Al}_{\mathrm{X}} \mathrm{N}$ by (a)

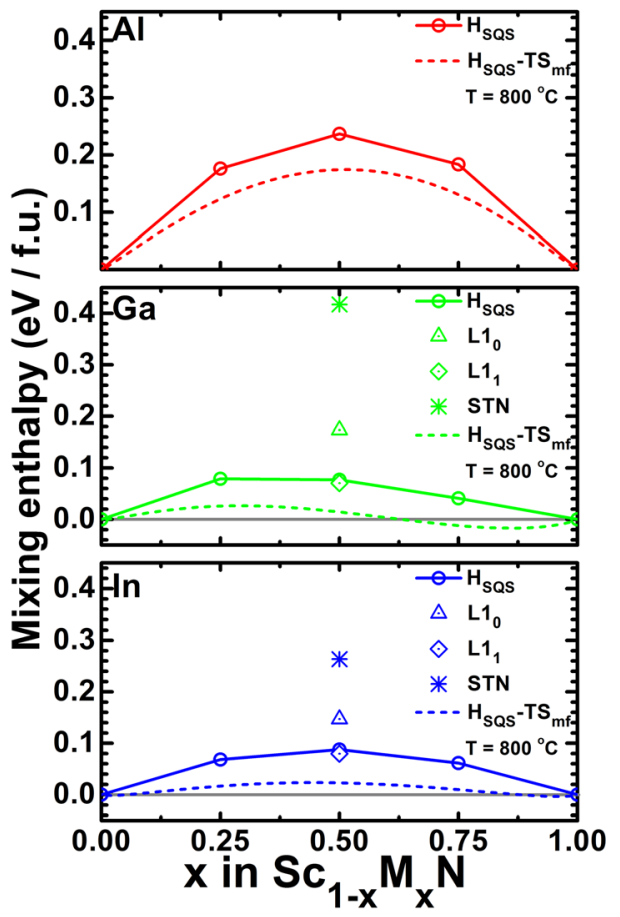

(b)

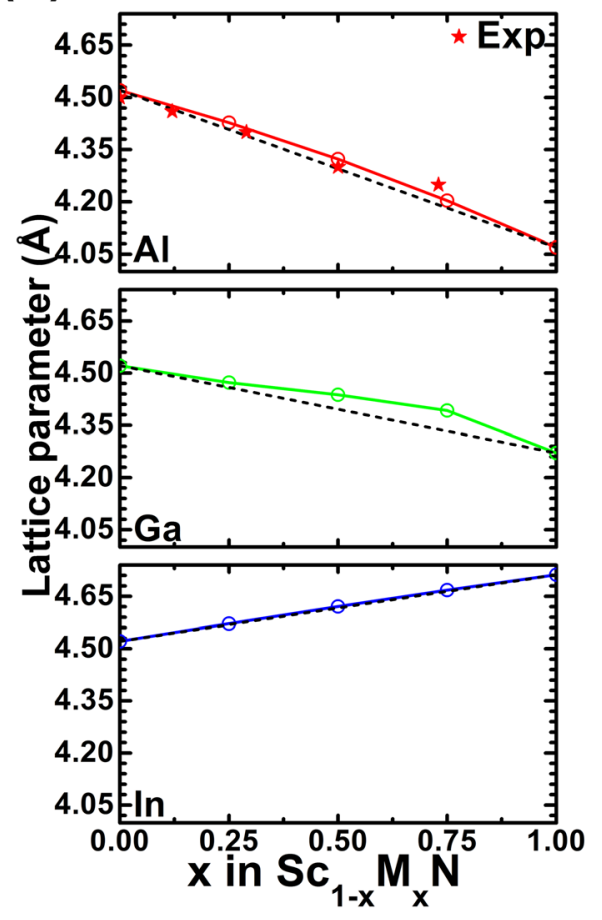

FIG. 5. (a) Comparison of the calculated mixing enthalpies of substitutionally disorder solid solution, B1- $\mathrm{L}_{0}$ and $\mathrm{B} 1-\mathrm{L} 1_{1}$ ordered solid solution and $\mathrm{ScTaN}_{2}$-type structure of $\mathrm{Sc}_{1-\mathrm{x}} \mathrm{M}_{\mathrm{x}} \mathrm{N}$, as a function of $\mathrm{MN}$ content where $\mathrm{M}=\mathrm{Al}, \mathrm{Ga}$, and $\mathrm{In}$, respectively. The value for $\mathrm{Sc}_{1-\mathrm{x}} \mathrm{Al}_{\mathrm{x}} \mathrm{N}$ obtained from Ref. 29. (b) Calculated equilibrium lattice parameter for rocksalt (B1) $\mathrm{Sc}_{1-\mathrm{x}} \mathrm{M}_{\mathrm{x}} \mathrm{N}$ solid solution as a function of $\mathrm{MN}$ content. The black line indicates Vegard's rule. The experimental lattice spacings obtained by Höglund et al. for $\mathrm{Sc}_{1-\mathrm{x}} \mathrm{Al}_{\mathrm{X}} \mathrm{N}$ is shown with stars. $^{28}$ 
reactive magnetron sputtering up to about $\mathrm{x}=0.50 .^{28,30}$ When subject to high temperature nucleation and growth of wurtzite, AlN was observed in domain boundaries. This contrasted to the observation of spinodal isostructural B1 decomposition in their comparison with $\mathrm{Ti}_{1-\mathrm{x}} \mathrm{Al}_{\mathrm{x}} \mathrm{N}$ system that was initiated already at temperatures around $800^{\circ} \mathrm{C} .{ }^{32}$ Furthermore, it has been shown that the crystal structure of as-deposited physically vapor deposited $\mathrm{Sc}_{1-\mathrm{x}} \mathrm{Al}_{\mathrm{x}} \mathrm{N}$ thin films exhibit wurtzite structure solid solution when the system is rich in $\mathrm{Al}^{60} \mathrm{~A}$ difference to $\mathrm{AlN}$ is that in $\mathrm{GaN}$ and $\mathrm{InN}$ the $\mathrm{B} 1$ phase is considerably higher in energy relative to the ground state $\mathrm{B} 4$ phase. In the case of GaN-rich $\mathrm{Sc}_{1-\mathrm{x}} \mathrm{Ga}_{\mathrm{x}} \mathrm{N}$, we observe unusually large local lattice relaxations in our supercell calculations, possibly indicating instability of the B1 phase in favor of a wurtzite alloy phase. Thus, non-isostructural phase separation is even more likely in $\mathrm{Sc}_{1-\mathrm{x}} \mathrm{Ga}_{\mathrm{x}} \mathrm{N}$ and $\mathrm{Sc}_{1-\mathrm{x}} \mathrm{In}_{\mathrm{x}} \mathrm{N}$ as compared to the previously studied system $\mathrm{Sc}_{1-\mathrm{x}} \mathrm{Al}_{\mathrm{x}} \mathrm{N}$.

\section{E. $S c_{1-x} L a_{x} N, S c_{1-x} G d_{x} N$, and $S c_{1-x} L u_{x} N$}

As representative examples of rare-earth-metal alloying, we have chosen La, Gd, and Lu with non-occupied $4 f$ states, half-filled $4 f$ states, and fully occupied $4 f$ states, respectively. Figure 6(a) shows the calculated mixing enthalpies of the $\mathrm{Sc}_{1-\mathrm{x}} \mathrm{La}_{\mathrm{x}} \mathrm{N}, \mathrm{Sc}_{1-\mathrm{x}} \mathrm{Gd}_{\mathrm{x}} \mathrm{N}$, and $\mathrm{Sc}_{1-\mathrm{x}} \mathrm{Lu}_{\mathrm{x}} \mathrm{N}$ solid solution. $\mathrm{Sc}_{1-\mathrm{x}} \mathrm{La}_{\mathrm{x}} \mathrm{N}$ shows a large positive mixing enthalpy with a maximum value of about $0.39 \mathrm{eV} / \mathrm{f}$.u. due to the very large lattice mismatch between $\mathrm{ScN}$ and $\mathrm{LaN}$ (Table I). $\mathrm{Sc}_{1-\mathrm{x}} \mathrm{Gd}_{\mathrm{x}} \mathrm{N}$ exhibits lower positive mixing enthalpy than $\mathrm{Sc}_{1-\mathrm{x}} \mathrm{La}_{\mathrm{x}} \mathrm{N}$ with a maximum value of $0.12 \mathrm{eV} / \mathrm{f}$.u. because GdN has a lattice parameter with a smaller difference to $\mathrm{ScN}$ (Table I). Thus, $\mathrm{Sc}_{1-\mathrm{x}} \mathrm{La}_{\mathrm{x}} \mathrm{N}$ and $\mathrm{Sc}_{1-\mathrm{x}} \mathrm{Gd}_{\mathrm{x}} \mathrm{N}$ have a tendency to phase separate due to an energetic driving force originating in volume mismatch. On the other hand, the mixing enthalpy of the solid solution in the $\mathrm{Sc}_{1-\mathrm{x}} \mathrm{Lu}_{\mathrm{x}} \mathrm{N}$ system shows small and negative mixing enthalpy which is understandable due to the small lattice mismatch between $\mathrm{ScN}$ and LuN allowing them to form a stable solid solution. The ordered $\mathrm{B} 1 \mathrm{Sc}_{1-\mathrm{x}} \mathrm{Lu}_{\mathrm{x}} \mathrm{N}$ phases at $\mathrm{x}=0.5$ are very close to the disordered solid solution and at temperatures of $800^{\circ} \mathrm{C}$ disordered solid solution is clearly favored as can be se from the estimated free energy curve. ScLaN and ScGdN, on the other hand, show negligible solubility in equilibrium even at that temperature. Their calculated lattice parameters with respect to composition in Figure 6(b) show that $\mathrm{Sc}_{1-\mathrm{x}} \mathrm{La}_{\mathrm{x}} \mathrm{N}$ and $\mathrm{Sc}_{1-\mathrm{x}} \mathrm{Gd}_{\mathrm{x}} \mathrm{N}$ have positive deviation from linear Vegard's rule. Especially $\mathrm{Sc}_{1-x} \mathrm{La}_{x} \mathrm{~N}$ has strong deviation, while $\mathrm{Sc}_{1-\mathrm{x}} \mathrm{Lu}_{\mathrm{x}} \mathrm{N}$ has a small negative deviation correlating with the mixing enthalpy behavior.

\section{F. $\mathrm{ScN}_{1-x} \mathrm{P}_{x}, \mathrm{ScN}_{1-x} \mathrm{As} \mathrm{s}_{x}$, and $\mathrm{ScN}_{1-x} \mathrm{Sb}_{x}$}

To give large impact on acoustic phonon scattering by solid solution effect, a large mass difference between host and alloy element is required. ${ }^{61,62}$ Considering $\mathrm{ScN}$, it would be highly beneficial if we can alloy by substituting on the $\mathrm{N}$ sublattice giving large mass difference. Elements intuitively suitable to choose as substitutes for $\mathrm{N}$ would be $\mathrm{P}, \mathrm{As}$, and $\mathrm{Sb}$, as they have the same number of valence electrons as $\mathrm{N}$. Moreover, the group-13 pnictides such as InN, InP, InAs, InSb, etc., are known semiconductors and one could expect similar behavior in a compound with Sc.

However, we need to know if it is reasonable to believe that they can form a solid solution with $\mathrm{ScN}$. Figure 7(a) shows the mixing enthalpies of $\mathrm{ScN}_{1-x} \mathrm{P}_{\mathrm{x}}, \mathrm{ScN}_{1-\mathrm{x}} \mathrm{As}_{\mathrm{x}}$, and $\mathrm{ScN}_{1-\mathrm{x}} \mathrm{Sb}_{\mathrm{x}}$ solid solution. The results show very large positive mixing enthalpies that are increasing following $\mathrm{P}$, As, or $\mathrm{Sb}$ substitute into $\mathrm{ScN}$. Therefore, the $\mathrm{ScN}_{1-\mathrm{x}} \mathrm{P}_{\mathrm{x}}$, $\mathrm{ScN}_{1-\mathrm{x}} \mathrm{As}_{\mathrm{x}}$, and $\mathrm{ScN}_{1-\mathrm{x}} \mathrm{Sb}_{\mathrm{x}}$ systems would prefer to phase (a)

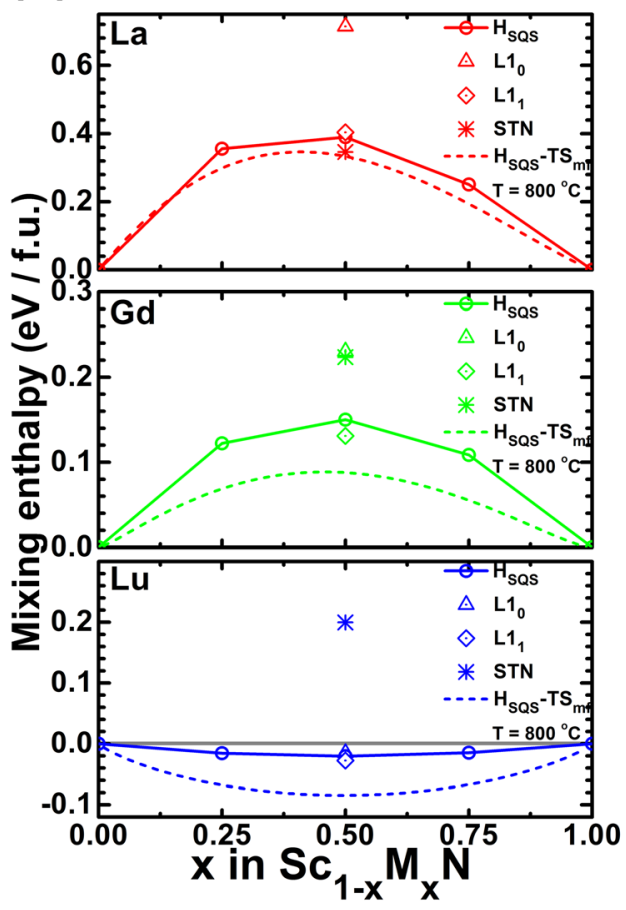

(b)

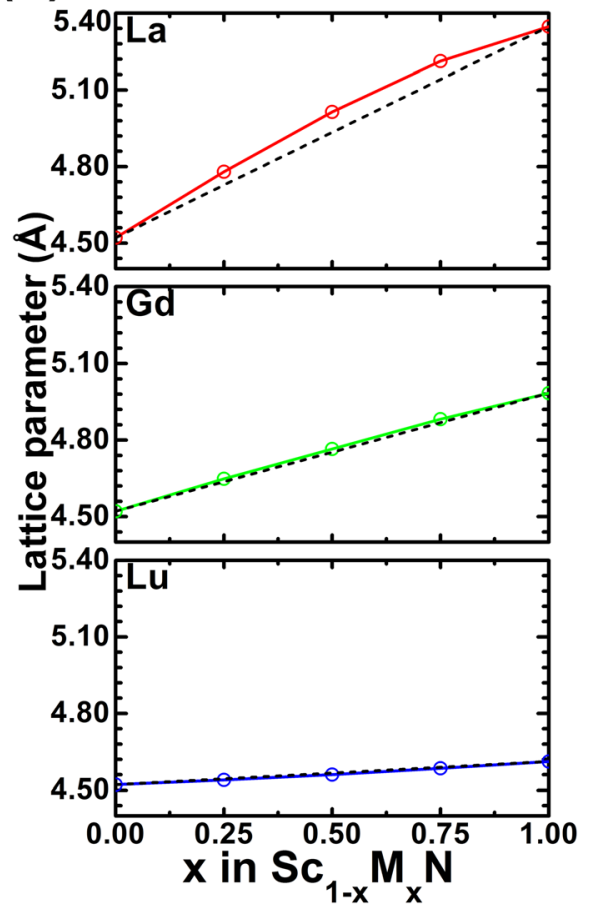

FIG. 6. (a) Comparison of the calculated mixing enthalpies of substitutionally disordered solid solution, B1-L1 $1_{0}$ and $\mathrm{B} 1-\mathrm{L} 1_{1}$ ordered solid solution and $\mathrm{ScTaN}_{2}$-type structure of $\mathrm{Sc}_{1-\mathrm{x}} \mathrm{M}_{\mathrm{x}} \mathrm{N}$, as a function of $\mathrm{MN}$ content where $\mathrm{M}=\mathrm{La}, \mathrm{Gd}$, and $\mathrm{Lu}$, respectively. (b) Calculated equilibrium lattice parameter for rocksalt (B1) $\mathrm{Sc}_{1-\mathrm{X}} \mathrm{M}_{\mathrm{X}} \mathrm{N}$ solid solution as a function of $\mathrm{MN}$ content where $\mathrm{M}=\mathrm{La}, \mathrm{Gd}$, and $\mathrm{Lu}$, respectively. The black line indicates Vegard's rule. 
(a)

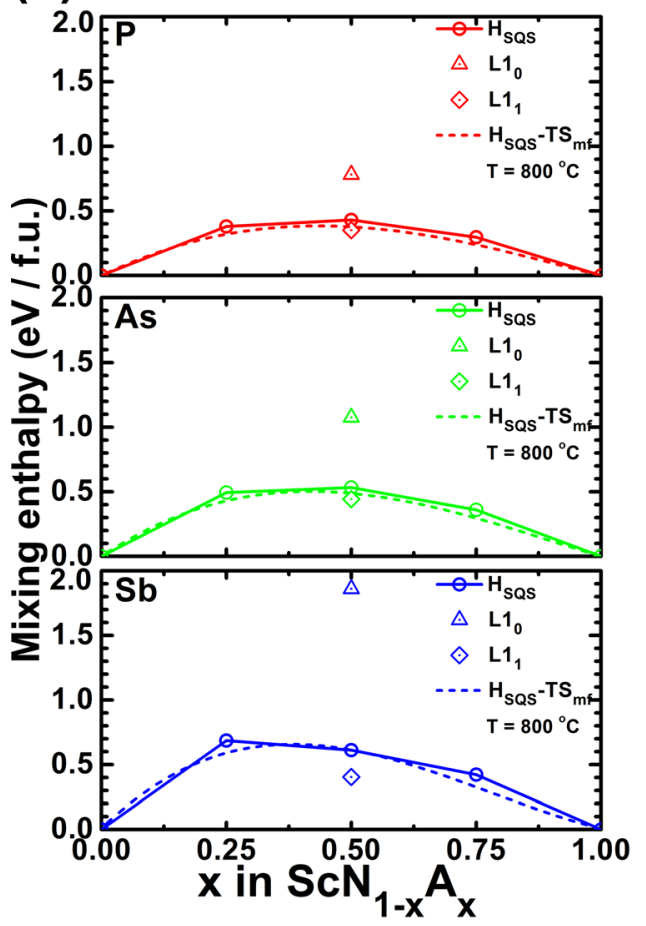

(b)

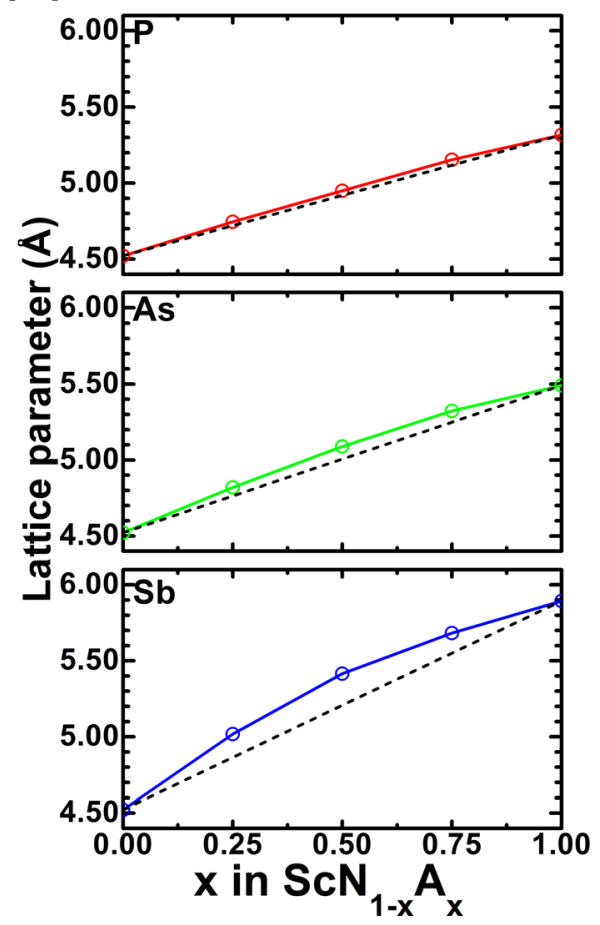

FIG. 7. (a) Comparison of the calculated mixing enthalpies of substitutionally disordered solid solution, B1-L1 $1_{0}$ and $\mathrm{B} 1-\mathrm{L} 1_{1}$ ordered solid solution and $\mathrm{ScTaN}_{2}$-type structure of $\mathrm{ScN}_{1-\mathrm{x}} \mathrm{A}_{\mathrm{x}}$, as a function of $\mathrm{ScA}$ content where $\mathrm{A}=\mathrm{P}, \mathrm{As}$, and $\mathrm{Sb}$, respectively. (b) Calculated equilibrium lattice parameter for rocksalt (B1) $\mathrm{ScN}_{1-\mathrm{x}} \mathrm{A}_{\mathrm{x}}$ solid solution as a function of ScA content where $\mathrm{A}=\mathrm{P}, \mathrm{As}$, and $\mathrm{Sb}$, respectively. The black line indicates Vegard's rule. separate rather than to form a solid solution. Since, P, As, and $\mathrm{Sb}$ have the valence electron as $\mathrm{N}$ the lattice mismatch will be the determining factor in the mixing energetics. When we consider the lattice mismatch between $\mathrm{ScN}$ and $\mathrm{ScP}$, ScAs, or $\mathrm{ScSb}$, the lattice mismatch is large in all cases and increasing with respect to change of element from $\mathrm{P}$ to $\mathrm{Sb}$ (Table I). Also the trend of lattice parameter variation over composition follows in the same manner; large lattice mismatch shows large positive deviation from linear Vegard's rule (See Figure 7(b)). Despite this fact, there are reports on highly mismatched metastable alloys $\mathrm{GaN}_{1-\mathrm{x}} \mathrm{As}_{\mathrm{x}}$ or $\mathrm{GaN}_{1-\mathrm{x}} \mathrm{Sb}_{\mathrm{x}}$ being possible to grow as solid solution in amorphous structure. ${ }^{63-65}$ Therefore, $\mathrm{ScN}_{1-\mathrm{x}} \mathrm{P}_{\mathrm{x}}, \mathrm{ScN}_{1-\mathrm{x}} \mathrm{As}_{\mathrm{x}}$, and $\mathrm{ScN}_{1-\mathrm{x}} \mathrm{Sb}_{\mathrm{x}}$ system could possibly behave in similar fashion. Furthermore, the effect of temperature at $\mathrm{T}=800^{\circ} \mathrm{C}$ shows a very small influence to this alloy family, i.e., the result still is a positive symmetric mixing free energy curve. This result indicates that these systems will phase separate also at high temperatures as soon as atomic diffusion is initiated.

\section{G. Summary and discussion}

To summarize all the results, Figure 8 shows an overview of the results of $0 \mathrm{~K}$ phase stability of $\mathrm{Sc}_{1-\mathrm{x}} \mathrm{M}_{\mathrm{x}} \mathrm{N}$ and $\mathrm{ScN}_{1-x} \mathrm{~A}_{\mathrm{x}}$ at $\mathrm{x}=0.50$. The results indicate that $\mathrm{Sc}_{1-\mathrm{x}} \mathrm{Y}_{\mathrm{x}} \mathrm{N}$, $\mathrm{Sc}_{1-\mathrm{x}} \mathrm{La}_{\mathrm{x}} \mathrm{N}, \mathrm{Sc}_{1-\mathrm{x}} \mathrm{Gd}_{\mathrm{x}} \mathrm{N}, \mathrm{Sc}_{1-\mathrm{x}} \mathrm{Ga}_{\mathrm{x}} \mathrm{N}$, and $\mathrm{Sc}_{1-\mathrm{x}} \mathrm{In}_{\mathrm{x}} \mathrm{N}$ for $\mathrm{Sc}$ sublattice and $\mathrm{ScN}_{1-\mathrm{x}} \mathrm{P}_{\mathrm{x}}, \mathrm{ScN}_{1-\mathrm{x}} \mathrm{P}_{\mathrm{x}}$, and $\mathrm{ScN}_{1-\mathrm{x}} \mathrm{Sb}_{\mathrm{x}}$ for $\mathrm{N}$ sublattice have an energetic driving force for phase separation due to volume mismatch. When the volume mismatch is small, the system shows tendency to form solid solution like $\mathrm{Sc}_{1-\mathrm{x}} \mathrm{Lu}_{\mathrm{x}} \mathrm{N}$. On the other hand, $\mathrm{Sc}_{1-\mathrm{x}} \mathrm{Ti}_{\mathrm{x}} \mathrm{N}, \mathrm{Sc}_{1-\mathrm{x}} \mathrm{Zr}_{\mathrm{x}} \mathrm{N}$, and $\mathrm{Sc}_{1-\mathrm{x}} \mathrm{Hf}_{\mathrm{x}} \mathrm{N}$ exhibit $\mathrm{B} 1-\mathrm{L} 1_{0}$ and $\mathrm{B} 1-\mathrm{L} 1_{1}$ ordered solid solution tendency because of low volume mismatch and the effect of electronic structure due to $d$ shell valence electron, as well as shown in $\mathrm{Sc}_{1-\mathrm{x}} \mathrm{V}_{\mathrm{x}} \mathrm{N}, \mathrm{Sc}_{1-\mathrm{x}} \mathrm{Nb}_{\mathrm{x}} \mathrm{N}$, and $\mathrm{Sc}_{1-\mathrm{x}} \mathrm{Ta}_{\mathrm{x}} \mathrm{N}$. Moreover, at $\mathrm{x}=0.50$ of $\mathrm{Sc}_{1-\mathrm{x}} \mathrm{V}_{\mathrm{x}} \mathrm{N}, \mathrm{Sc}_{1-\mathrm{x}} \mathrm{Nb}_{\mathrm{x}} \mathrm{N}$, and $\mathrm{Sc}_{1-\mathrm{x}} \mathrm{Ta}_{\mathrm{x}} \mathrm{N}$ system can form $\mathrm{ScTaN}_{2}$-type structure as the most competitive phase. However, all these results come from $0 \mathrm{~K}$ DFT calculations alone. Our objective of this study is to obtain information about the phase stability of $\mathrm{ScN}$ based solid solution at temperatures where diffusion could be active to select a suitable element and strategy in thermal conductivity reduction for thermoelectric medium to high temperature application of $\mathrm{ScN}$. Therefore, we need to consider these results at elevated temperature.

Figure 9 shows the results of phase stability of $\mathrm{Sc}_{1-\mathrm{x}} \mathrm{M}_{\mathrm{x}} \mathrm{N}$ and $\mathrm{ScN}_{1-\mathrm{x}} \mathrm{A}_{\mathrm{x}}$ for $\mathrm{x}=0.50$ at estimated temperature effect at $\mathrm{T}=800{ }^{\circ} \mathrm{C}$ which is a typical temperature where metal sublattice diffusion has been reported to be activated in mixed nitrides. The results show that at $x=0.50$ and

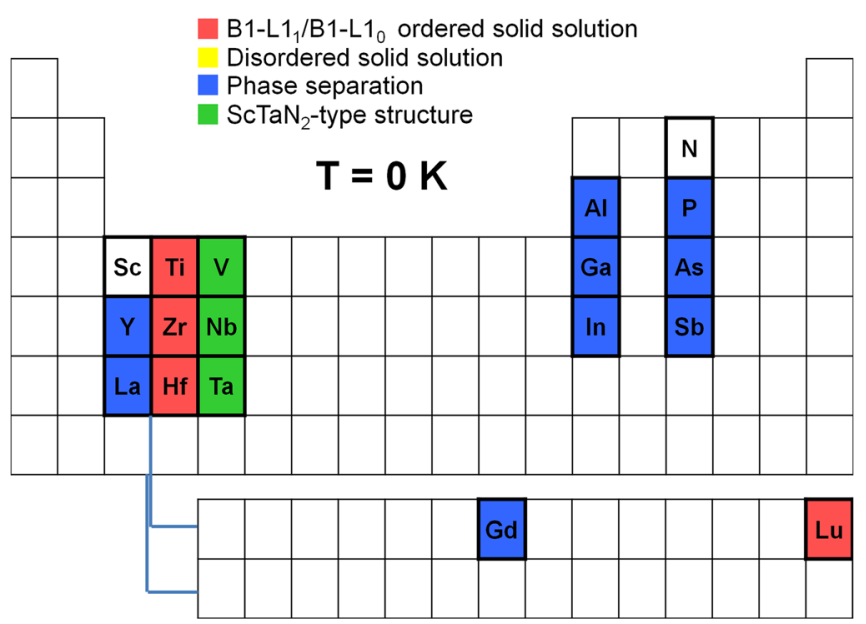

FIG. 8. Summary of phase stability of ScN-based solid solution at $\mathrm{x}=0.50$ and $\mathrm{T}=0 \mathrm{~K}$. 


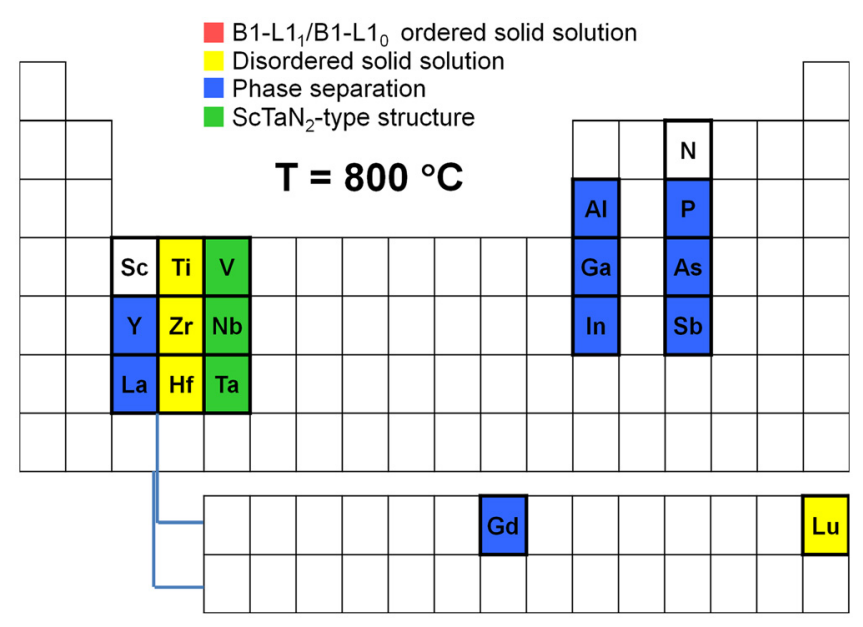

FIG. 9. Summary of phase stability of ScN-based solid solution at $\mathrm{x}=0.50$ and $\mathrm{T}=800^{\circ} \mathrm{C}$.

$\mathrm{T}=800^{\circ} \mathrm{C}, \quad \mathrm{Sc}_{1-\mathrm{x}} \mathrm{Ti}_{\mathrm{x}} \mathrm{N}, \quad \mathrm{Sc}_{1-\mathrm{x}} \mathrm{Zr}_{\mathrm{x}} \mathrm{N}, \quad \mathrm{Sc}_{1-\mathrm{x}} \mathrm{Hf}_{\mathrm{x}} \mathrm{N}, \quad$ and $\mathrm{Sc}_{1-\mathrm{x}} \mathrm{Lu}_{\mathrm{x}} \mathrm{N}$ system have changed their phase from $\mathrm{B} 1-\mathrm{L} 1_{0}$ and $\mathrm{B} 1-\mathrm{L} 1_{1}$ ordered solid solution to a disordered solid solution. However, also after inclusion of the effect of temperature the $\mathrm{Sc}_{1-\mathrm{x}} \mathrm{V}_{\mathrm{x}} \mathrm{N}, \mathrm{Sc}_{1-\mathrm{x}} \mathrm{Nb}_{\mathrm{x}} \mathrm{N}$, and $\mathrm{Sc}_{1-\mathrm{x}} \mathrm{Ta}_{\mathrm{x}} \mathrm{N}$ system still have $\mathrm{ScTaN}_{2}$-type structure stable meaning that $\mathrm{ScTaN}_{2}$ type structure is stable at this considered temperature.

The results that show in Figure 8 suggest the suitable strategies for $\mathrm{ScN}$ lattice thermal conductivity reduction for thermoelectric application. First, Lu is a suitable element for lattice thermal conductivity reduction by solid solution. $\mathrm{Sc}_{1-\mathrm{x}} \mathrm{Lu}_{\mathrm{x}} \mathrm{N}$ is stable as solid solution at $\mathrm{T}=800^{\circ} \mathrm{C}$ and $\mathrm{Lu}$ is a heavy element compared to $\mathrm{Sc}$ and N. Furthermore, Lu has the same number of valence electrons as Sc, therefore, there is no doping effect unlike when $\mathrm{ScN}$ form solid solution with $\mathrm{Ti}, \mathrm{Zr}$, Hf. The latter should be considered only when intentional electron doping is desired. One should keep in mind that such alloying could give a side effect of Seebeck coefficient reduction yielding no improvement or even decreasing the value of the thermoelectric figure of merit $Z T$. The tendency of mixing of TiN/ZrN/HfN and $\mathrm{ScN}$ should also be kept in mind when designing superlattices between them as the transformation of these superlattices to a metallic solid solution would destroy their thermoelectric performance completely. ${ }^{51}$

A second strategy is using inclusions to reduce lattice thermal conductivity. The results indicate that we can use Y, $\mathrm{La}, \mathrm{Gd}, \mathrm{Al}, \mathrm{Ga}$, In, P, As, and Sb, since these systems have phase separation tendency and they tend to have isostructural, possibly semi-coherent, interfaces after the decomposition which should have minor effects on carrier mobility. Moreover, we can use these results to suggest a good nitride material for superlattice to reduce lattice thermal conductivity and enhancing power factor, i.e., using $\mathrm{YN}, \mathrm{LaN}, \mathrm{GdN}$, $\mathrm{ScP}, \mathrm{ScAs}$, or $\mathrm{ScSb}$ forming alternating layer with $\mathrm{ScN}$, since all of them prefer to phase separate and have similar crystal structure as $\mathrm{ScN}$. Even at high working temperature, they should thus not intermix and degrade the thermoelectric properties. Finally, the $\mathrm{ScTaN}_{2}$-type inherently nanolaminated structures could potentially be promising structure for thermoelectric application in themselves, since they are thermodynamically stable and have been reported to have semimetallic character. ${ }^{45}$ Thus, $\mathrm{Nb}$ or $\mathrm{Ta}$ is a good choice to use for $\mathrm{ScTaN}_{2}$-type structures since both of them have heavy mass difference which give more effect on lattice thermal conductivity reduction as compared to $\mathrm{V}$.

\section{CONCLUSIONS}

We have used density functional theory calculations to investigate the effect of mixing thermodynamic in order to determine phase stability of ScN-based solid solutions of relevance for lattice thermal conductivity reduction in thermoelectric applications. Our results demonstrate that at $\mathrm{T}=800^{\circ} \mathrm{C}$ the free energy of mixing for $\mathrm{Sc}_{1-\mathrm{x}} \mathrm{Y}_{\mathrm{x}} \mathrm{N}$, $\mathrm{Sc}_{1-x} \mathrm{La}_{\mathrm{x}} \mathrm{N}, \mathrm{Sc}_{1-\mathrm{x}} \mathrm{Gd}_{\mathrm{x}} \mathrm{N}, \mathrm{Sc}_{1-\mathrm{x}} \mathrm{Ga}_{\mathrm{x}} \mathrm{N}$, and $\mathrm{Sc}_{1-\mathrm{x}} \mathrm{In}_{\mathrm{x}} \mathrm{N}$ for $\mathrm{Sc}$ sublattice and $\mathrm{ScP}_{1-\mathrm{x}} \mathrm{N}_{\mathrm{x}}, \mathrm{ScAs}_{1-\mathrm{x}} \mathrm{N}_{\mathrm{x}}$, and $\mathrm{ScSb}_{1-\mathrm{x}} \mathrm{N}_{\mathrm{x}}$ for $\mathrm{N}$ sublattice still have phase separation tendency at high temperature. In addition, the $\mathrm{ScTaN}_{2}$-type structure in the $\mathrm{Sc}_{1-\mathrm{x}} \mathrm{V}_{\mathrm{x}} \mathrm{N}, \mathrm{Sc}_{1-\mathrm{x}} \mathrm{Nb}_{\mathrm{x}} \mathrm{N}$, and $\mathrm{Sc}_{1-\mathrm{x}} \mathrm{Ta}_{\mathrm{x}} \mathrm{N}$ systems is also stable at high temperature. On the other hand, at $800^{\circ} \mathrm{C}$ $\mathrm{Sc}_{1-\mathrm{x}} \mathrm{Ti}_{\mathrm{x}} \mathrm{N}, \mathrm{Sc}_{1-\mathrm{x}} \mathrm{Zr}_{\mathrm{x}} \mathrm{N}, \mathrm{Sc}_{1-\mathrm{x}} \mathrm{Hf}_{\mathrm{x}} \mathrm{N}$, and $\mathrm{Sc}_{1-\mathrm{x}} \mathrm{Lu}_{\mathrm{x}} \mathrm{N}$ systems are predicted to be thermodynamically stable in disordered $\mathrm{B} 1$ solid solutions rather than in the $\mathrm{B} 1-\mathrm{L} 1_{0}$ and $\mathrm{B} 1-\mathrm{L} 1_{1}$ ordered solid solutions stable at $0 \mathrm{~K}$.

From these results, we are able to suggest suitable materials for the different possible strategies for reduction of the lattice thermal conductivity of ScN. Since, Lu has tendency to mix with $\mathrm{ScN}$ and Lu does not give doping effect after mixing due to it has the same valance electron as $\mathrm{ScN}$, thus, $\mathrm{Sc}_{1-\mathrm{x}} \mathrm{Lu}_{\mathrm{x}} \mathrm{N}$ system can be used for solid solution strategy. Next, Y, La, Gd, Al, Ga, In, P, As, and Sb, have phase separation tendency when they mix with $\mathrm{ScN}$, therefore, they are a good system for a nano-inclusion strategy. YN, LaN, and $\mathrm{GdN}$ or $\mathrm{ScP}, \mathrm{ScAs}$, and $\mathrm{ScSb}$ can be used for making a superlattice with $\mathrm{ScN}$, since, they are not tending to intermixing at high temperature and are isostructural with $\mathrm{ScN}$. The mixing thermodynamics of the considered alloy systems can be understood by considering the effect of the factors of volume mismatch, favoring phase separation, and an electronic structure effect of delocalization of extra $d$-electrons to empty Sc $3 d-t 2 g$ states, favoring mixing.

\section{ACKNOWLEDGMENTS}

The authors would like to acknowledge funding from the Swedish Research Council (VR) through Grant Nos. 621-2009-5258, 621-2012-4430, and 621-2011-4417 and the Linnaeus Strong Research Environment LiLi-NFM, the Swedish Foundation for Strategic Research (Ingvar Carlsson Award 3), and the Linköping Center in Nanoscience and technology (CeNano). The calculations were performed using computer resources provided by the Swedish national infrastructure for computing (SNIC) at the National Supercomputer Centre (NSC).

${ }^{1}$ D. Gall, I. Petrov, N. Hellgren, L. Hultman, J. E. Sundgren, and J. E. Greene, J. Appl. Phys. 84, 6034 (1998).

${ }^{2}$ D. Gall, M. Städele, K. Järrendahl, I. Petrov, P. Desjardins, R. T. Haasch, T. Y. Lee, and J. E. Greene, Phys. Rev. B 63, 125119 (2001).

${ }^{3}$ W. R. L. Lambrecht, Phys. Rev. B 62, 13538 (2000). 
${ }^{4}$ C. Stampfl, W. Mannstadt, R. Asahi, and A. J. Freeman, Phys. Rev. B 63, 155106 (2001).

${ }^{5}$ H. A. Al-Brithen, A. R. Smith, and D. Gall, Phys. Rev. B 70, 045303 (2004). ${ }^{6}$ J. P. Dismukes, W. M. Yim, J. J. Tietjen, and R. E. Novak, RCA Review 31, 680 (1970).

${ }^{7}$ J. M. Gregoire, S. D. Kirby, G. E. Scopelianos, F. H. Lee, and R. B. van Dover, J. Appl. Phys. 104, 074913 (2008).

${ }^{8}$ S. Kerdsongpanya et al., Appl. Phys. Lett. 99, 232113 (2011).

${ }^{9}$ P. V. Burmistrova, J. Maassen, T. Favaloro, B. Saha, S. Salamat, Y. R. Koh, M. S. Lundstrom, A. Shakouri, and T. D. Sands, J. Appl. Phys. 113, 153704 (2013).

${ }^{10}$ G. J. Snyder and E. S. Toberer, Nature Mater. 7, 105 (2008).

${ }^{11}$ L. M. Goncalves, C. Couto, P. Alpuim, A. G. Rolo, F. Völklein, and J. H. Correia, Thin Solid Films 518, 2816 (2010).

${ }^{12}$ J. R. Sootsman, H. Kong, C. Uher, J. J. D’Angelo, C.-I. Wu, T. P. Hogan, T. Caillat, and M. G. Kanatzidis, Angew. Chem., Int. Ed. 47, 8618 (2008).

${ }^{13}$ S. Kerdsongpanya, B. Alling, and P. Eklund, Phys. Rev. B 86, 195140 (2012).

${ }^{14}$ V. Rawat, Y. K. Koh, D. G. Cahill, and T. D. Sands, J. Appl. Phys. 105, 024909 (2009).

${ }^{15}$ C. J. Vineis, A. Shakouri, A. Majumdar, and M. G. Kanatzidis, Adv. Mater. 22, 3970 (2010).

${ }^{16}$ A. Shakouri, Annu. Rev. Mater. Res. 41, 399 (2011).

${ }^{17}$ H. Böttner, G. Chen, and R. Venkatasubramanian, MRS Bull. 31, 211 (2006).

${ }^{18}$ E. S. Toberer, L. L. Baranowski, and C. Dames, Annu. Rev. Mater. Res. 42, 179 (2012)

${ }^{19}$ K. Biswas, J. He, Q. Zhang, G. Wang, C. Uher, V. P. Dravid, and M. G. Kanatzidis, Nat. Chem. 3, 160 (2011).

${ }^{20}$ G. Zeng et al., J. Appl. Phys. 101, 034502 (2007).

${ }^{21}$ H. B. Radousky and H. Liang, Nanotechnology 23, 502001 (2012).

${ }^{22}$ J.-F. Li, W.-S. Liu, L.-D. Zhao, and M. Zhou, NPG Asia Mater. 2, 152 (2010).

${ }^{23}$ C. Nordling and J. Österman, Physics Handbook for Science and Engineering (Studentlitteratur, Poland, 2007).

${ }^{24}$ L. Hultman, Vacuum 57, 1 (2000).

${ }^{25}$ P. H. Mayrhofer, C. Mitterer, L. Hultman, and H. Clemens, Prog. Mater. Sci. 51, 1032 (2006).

${ }^{26}$ R. Rachbauer, D. Holec, and P. H. Mayrhofer, Surf. Coat. Technol. 211, 98 (2012).

${ }^{27}$ C. Wüstefeld, D. Rafaja, M. Dopita, M. Motylenko, C. Baehtz, C. Michotte, and M. Kathrein, Surf. Coat. Technol. 206, 1727 (2011).

${ }^{28}$ C. Höglund, B. Alling, J. Birch, M. Beckers, P. O. A. Persson, C. Baehtz, Z. Czigány, J. Jensen, and L. Hultman, Phys. Rev. B 81, 224101 (2010).

${ }^{29}$ B. Alling, A. Karimi, and I. A. Abrikosov, Surf. Coat. Technol. 203, 883 (2008).

${ }^{30}$ C. Höglund, J. Bareño, J. Birch, B. Alling, Z. Czigány, and L. Hultman, J. Appl. Phys. 105, 113517 (2009).

${ }^{31}$ F. Rovere, D. Music, S. Ershov, M. t. Baben, H.-G. Fuss, P. H. Mayrhofer, and J. M. Schneider, J. Phys. D: Appl. Phys. 43, 035302 (2010).

${ }^{32}$ B. Alling, A. V. Ruban, A. Karimi, O. E. Peil, S. I. Simak, L. Hultman, and I. A. Abrikosov, Phys. Rev. B 75, 045123 (2007).

${ }^{33}$ F. Tian, J. D'Arcy-Gall, T. Y. Lee, M. Sardela, D. Gall, I. Petrov, and J. E. Greene, J. Vac. Sci. Technol. A 21, 140 (2003).
${ }^{34}$ A. Wang, S.-L. Shang, Y. Du, L. Chen, J. Wang, and Z.-K. Liu, J. Mater. Sci. 47, 7621 (2012).

${ }^{35}$ W. Kohn and L. J. Sham, Phys. Rev. 140, A1133 (1965).

${ }^{36}$ P. E. Blöchl, Phys. Rev. B 50, 17953 (1994).

${ }^{37}$ G. Kresse and J. Furthmüller, Phys. Rev. B 54, 11169 (1996).

${ }^{38}$ G. Kresse and D. Joubert, Phys. Rev. B 59, 1758 (1999).

${ }^{39}$ J. P. Perdew, K. Burke, and M. Ernzerhof, Phys. Rev. Lett. 77, 3865 (1996).

${ }^{40}$ S. L. Dudarev, G. A. Botton, S. Y. Savrasov, C. J. Humphreys, and A. P. Sutton, Phys. Rev. B 57, 1505 (1998).

${ }^{41}$ P. Larson, W. R. L. Lambrecht, A. Chantis, and M. van Schilfgaarde, Phys. Rev. B 75, 045114 (2007).

${ }^{42}$ A. Zunger, S. H. Wei, L. G. Ferreira, and J. E. Bernard, Phys. Rev. Lett. 65, 353 (1990).

${ }^{43}$ A. V. Ruban and I. A. Abrikosov, Rep. Prog. Phys. 71, 046501 (2008).

${ }^{44}$ B. Alling, C. Hoglund, R. Hall-Wilton, and L. Hultman, Appl. Phys. Lett. 98, 241911 (2011).

${ }^{45}$ R. Niewa, D. A. Zherebtsov, W. Schnelle, and F. R. Wagner, Inorg. Chem. 43, 6188 (2004).

${ }^{46}$ W. Lengauer, J. Solid State Chem. 82, 186 (1989).

${ }^{47}$ H. Imai, Y. Shimakawa, and Y. Kubo, Phys. Rev. B 64, 241104 (2001).

${ }^{48}$ I. Terasaki, Y. Sasago, and K. Uchinokura, Phys. Rev. B 56, R12685 (1997).

${ }^{49}$ K. Koumoto, I. Terasaki, and R. Funahashi, MRS Bull. 31, 206 (2006).

${ }^{50}$ J. M. Gregoire, S. D. Kirby, M. E. Turk, and R. B. van Dover, Thin Solid Films 517, 1607 (2009).

${ }^{51}$ B. Saha, J. Acharya, T. D. Sands, and U. V. Waghmare, J. Appl. Phys. 107, 033715 (2010).

${ }^{52}$ D. Gall, M. Stoehr, and J. E. Greene, Phys. Rev. B 64, 174302 (2001).

${ }^{53}$ C. Ravi, Calphad 33, 469 (2009).

${ }^{54}$ E. Zhao, B. Hong, J. Meng, and Z. Wu, J. Comput. Chem. 30, 2358 (2009).

${ }^{55}$ G.-i. Oya and Y. Onodera, J. Appl. Phys. 47, 2833 (1976).

${ }^{56}$ D. Holec, R. Franz, P. H. Mayrhofer, and C. Mitterer, J. Phys. D: Appl. Phys. 43, 145403 (2010).

${ }^{57}$ H. Vollstädt, E. Ito, M. Akaishi, S.-i. Akimoto, and O. Fukunaga, Proc. Jpn. Acad., Ser. B: Phys. Biol. Sci. 66, 7 (1990).

${ }^{58}$ V. Rawat, D. N. Zakharov, E. A. Stach, and T. D. Sands, Phys. Rev. B 80, 024114 (2009).

${ }^{59}$ M. Ueno, M. Yoshida, A. Onodera, O. Shimomura, and K. Takemura, Phys. Rev. B 49, 14 (1994).

${ }^{60}$ C. Hoglund, J. Birch, B. Alling, J. Bareno, Z. Czigany, P. O. A. Persson, G. Wingqvist, A. Zukauskaite, and L. Hultman, J. Appl. Phys. 107, 123515 (2010).

${ }^{61}$ P. G. Klemens, Phys. Rev. 119, 507 (1960).

${ }^{62}$ P. G. Klemens, Int. J. Thermophys. 22, 265 (2001).

${ }^{63}$ S. V. Novikov et al., J. Vac. Sci. Technol. B 31, 03 C102 (2013).

${ }^{64}$ K. M. Yu et al., Appl. Phys. Lett. 102, 102104 (2013).

${ }^{65}$ A. X. Levander et al., J. Mater. Res. 26, 2887 (2011).

${ }^{66}$ D. Holec, M. Friák, J. Neugebauer, and P. H. Mayrhofer, Phys. Rev. B 85, 064101 (2012).

${ }^{67}$ M. A. Scarpulla, C. S. Gallinat, S. Mack, J. S. Speck, and A. C. Gossard, J. Cryst. Growth 311, 1239 (2009).

${ }^{68}$ W. M. Yim, E. J. Stofko, and R. T. Smith, J. Appl. Phys. 43, 254 (1972). 